\title{
Inflammatory and infectious manifestations of immunodeficiency in the gastrointestinal tract
}

\author{
Nicole C. Panarelli ${ }^{1} \cdot$ Rhonda K. Yantiss ${ }^{2}$
}

Received: 10 July 2017 / Revised: 24 November 2017 / Accepted: 11 December 2017 / Published online: 5 February 2018

(c) United States \& Canadian Academy of Pathology 2018

\begin{abstract}
Immune compromise may result from genetic abnormalities, HIV/AIDS, or consequences of therapy for neoplastic and autoimmune diseases. Many immunocompromised patients develop severe gastrointestinal symptoms, particularly diarrhea, accompanied by non-specific or mild endoscopic abnormalities; mucosal biopsy with pathologic interpretation has a major role in the diagnosis and management of these patients. Immunocompromised individuals are at risk for all the diseases that affect those with a healthy immune system, but they are also prone to other illnesses that rarely affect immunocompetent patients. This review discusses the gastrointestinal manifestations of primary and acquired immunodeficiency, chemotherapy-related injury, and infections that show a predilection for immunocompromised patients. Key histologic features and relevant differential diagnoses are emphasized.
\end{abstract}

\section{Introduction}

Histologic examination of mucosal biopsy samples plays an increasingly important role in the diagnosis and management of patients who experience complications of immunosuppression owing to a variety of genetic, acquired, and iatrogenic causes. Patients with various types of primary immunodeficiency are prone to gastrointestinal injury, and the inflammatory changes often mimic more common disorders, such as celiac disease, idiopathic inflammatory bowel disease, medication-related injury, and autoimmune enteropathy (Table 1). Immunocompromised patients are also at increased risk for opportunistic infections and neoplasia, particularly lymphomas. Pathologic evaluation can help (1) distinguish immunodeficiency states from autoimmune disorders, (2) identify potentially serious complications of therapeutic immunosuppression, including graftversus-host disease and drug toxicity, and (3) facilitate the diagnosis of superimposed viral, bacterial, fungal, and parasitic infections.

Rhonda K. Yantiss

npanarel@montefiore.org

1 Albert Einstein College of Medicine, Bronx, NY, USA

2 Weill Cornell Medicine, New York, NY, USA

\section{Primary immunodeficiency disorders}

\section{Common variable immunodeficiency}

Common variable immunodeficiency is characterized by chronic, recurrent infections that result from a diminished capacity to produce and secrete antibodies. Diagnostic criteria include reduced serum immunoglobulin $(\mathrm{Ig}) \mathrm{G}$, IgA, and/or IgM levels ( $>2$ standard deviations below mean for age), absent isohemagglutinins and/or poor response to vaccines, and onset of immunodeficiency at age $>2$ years [1]. Affected patients have variably diminished humoral and cellular immunity, resulting from defects in genes that drive B-cell differentiation and activation, effector T-cell response, and immune tolerance [2]. Most cases are sporadic, although forms of the disease follow autosomal dominant and autosomal recessive patterns of inheritance [2]. Gastrointestinal symptoms, particularly watery diarrhea, are common, being second only to recurrent sinopulmonary infections as a cause of disease-related morbidity [3]. Patients are predisposed to develop immune-mediated conditions, such as autoimmune thrombocytopenia, rheumatoid arthritis, and primary biliary cirrhosis; they are also at increased risk for gastrointestinal B-cell lymphoma and adenocarcinoma [3, 4]. Endoscopic findings are variable; the mucosa may be normal or show diffuse erythema, friability, and ulcers [5]. Lymphoid hyperplasia with mucosal nodularity is common, particularly the duodenum [6]. 
Common variable immunodeficiency can affect any part of the gastrointestinal tract. Gastric manifestations include corpus-predominant autoimmune gastritis, autoimmune pan-gastritis, and lymphocytic gastritis. Duodenal crypt and villous architectural abnormalities accompanied by intraepithelial lymphocytosis closely resemble celiac disease; this differential diagnosis can be particularly problematic because some afflicted patients have spuriously elevated anti-tissue transglutaminase, anti-gliadin, and antiendomysial antibody titers [5, 7]. Patchy chronic active enterocolitis with lymphoid hyperplasia and granulomata mimic Crohn disease most commonly, although colonic intraepithelial lymphocytosis and patchy subepithelial collagen deposition have also been described.

Biopsy samples typically display markedly decreased numbers of plasma cells in combination with intraepithelial lymphocytosis that tends to be more pronounced in the deep mucosa than superficial epithelium, apoptotic crypt epithelial cells, lymphoid hyperplasia, architectural distortion, and granulomata (Fig. 1). The lamina propria may seem slightly paucicellular, particularly when patients do not have concomitant infections. Neutrophils are present in the lamina propria and epithelium, but high numbers usually signify the presence of infection, particularly candidiasis or cytomegaloviral infection. Patients with common variable immunodeficiency are also at increased risk for Cryptosporium spp. infection and chronic, or recurrent, giardiasis $[8,9]$. Importantly, the presence of plasma cells does not exclude a diagnosis of common variable immunodeficiency; approximately one-third of biopsy samples contain plasma cells [8].

The differential diagnosis of common variable immunodeficiency includes several de novo immune-mediated inflammatory conditions, particularly celiac disease, autoimmune enteropathy, and inflammatory bowel disease. However, all of these entities are readily distinguished from the former because they uniformly elicit plasma cell-rich inflammation in the lamina propria, which is not a feature of common variable immunodeficiency. Apoptotic crypt epithelial cells are frequently encountered in both common variable immunodeficiency and autoimmune enteropathy; their presence in high numbers is not typical of either celiac disease or inflammatory bowel disease. Prominent lymphoid hyperplasia, cytomegalovirus (CMV) infection, and giardiasis are uncommon among untreated patients with de novo immune-mediated inflammatory conditions. Their detection in mucosal biopsy samples should prompt suspicion for an underlying immunodeficiency.

\section{Selective $\lg A$ deficiency}

Selective $\operatorname{IgA}$ deficiency is the most common primary immunodeficiency, but a substantial proportion of affected

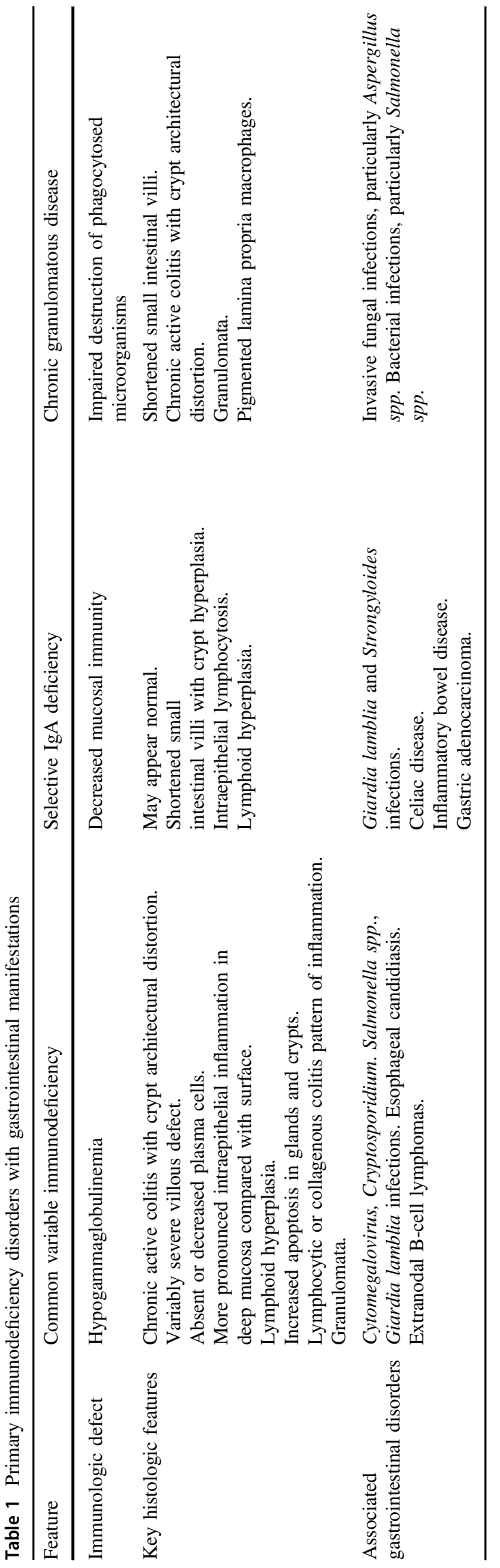


Fig. 1 A colonic biopsy sample from a patient with common variable immunodeficiency shows a paucicellular lamina propria that contains a minute epithelioid granuloma (arrow) a Numerous apoptotic bodies are present in the deep crypt regions, and the lamina propria displays an absence of plasma cells b. (Hematoxylin and eosin; original magnification: $\times 100$ a; $\times 400$ b)
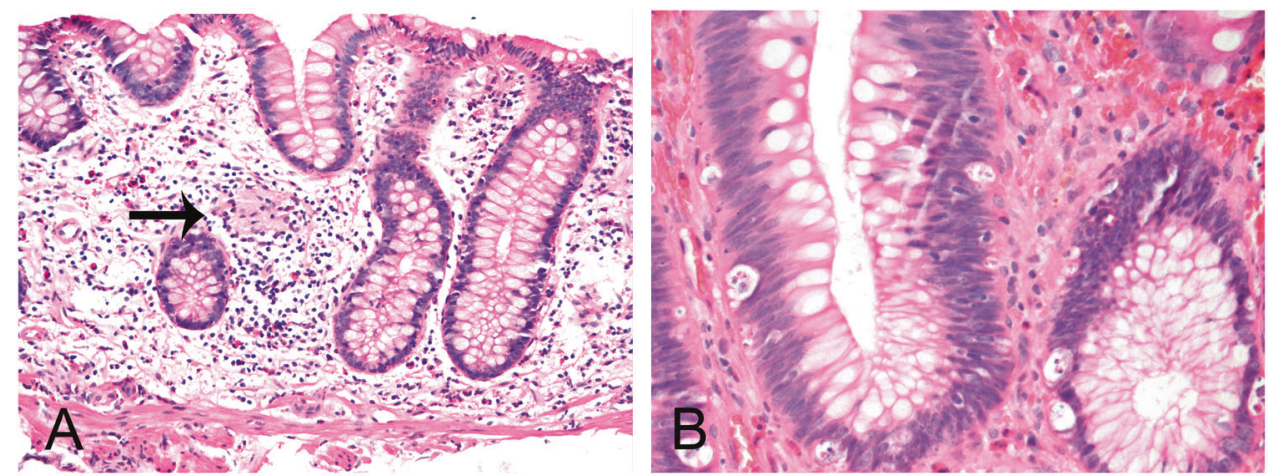

individuals are asymptomatic [10]. This disorder results from defective maturation of $\operatorname{IgA}$-secreting plasma cells, leading to decreased mucosal immunoglobulin secretion. Symptomatic patients develop recurrent sinopulmonary and gastrointestinal infections, particularly giardiasis and strongyloidiasis. Patients are also at risk for other immunemediated disorders, particularly celiac disease. In fact, $2-3 \%$ of patients with celiac disease are IgA-deficient, an approximately 10 -fold higher prevalence than that of the general population [11]. Serologic screening tests that target IgA endomysial antibodies are not accurate when used to test IgA-deficient patients for celiac disease; IgG antibodies to deaminated gliadin peptides and tissue transglutaminase are more useful [12]. Treatment consists of antibiotic therapy for recurrent infections as well as dietary modification and gluten withdrawal for patients with celiac disease.

Gastrointestinal biopsy samples are often histologically normal, or show lymphoid hyperplasia, especially in the duodenum; duodenal lymphoid hyperplasia should always prompt evaluation for the possibility of a primary immunodeficiency. Inflammatory changes, such as granulomata and chronic mucosal injury that simulate idiopathic inflammatory bowel disease, have been reported among patients with $\operatorname{IgA}$ deficiency, but are uncommon [13]. Patients with IgA deficiency and celiac disease usually have duodenal abnormalities that are indistinguishable from those of celiac disease that develops in immunocompetent individuals. Gluten withdrawal results in improvement of gastrointestinal symptoms for most patients.

\section{Chronic granulomatous disease}

Chronic granulomatous disease is a rare genetic disorder characterized by severe, recurrent bacterial and fungal infections. Patients inherit either X-linked or autosomal recessive defects in genes encoding components of the NADPH oxidase complex that normally kills ingested microorganisms. Digestion of other exogenous materials is also attenuated, so many patients have mucosal biopsy samples that show chronic granulomatous inflammation in the absence of infection. Between 32 and $48 \%$ of patients with chronic granulomatous disease have gastrointestinal complaints, including diarrhea, abdominal pain, constipation, and failure to thrive [14]. Endoscopic findings are usually non-specific, but a "leopard skin" pattern of brown patches against yellow colonic mucosa has been described [15]. Histologic features of chronic granulomatous disease overlap with those of Crohn disease (Fig. 2), although the former typically shows aggregates of pigmented macrophages in the lamina propria that can be a helpful diagnostic clue [16]. Data from a large study of 102 patients with chronic granulomatous disease suggest a high frequency of chronic colitis $(55 \%)$, granulomata $(60 \%)$, and pigmented macrophages (74\%); small bowel biopsy samples showed frequent mucosal eosinophilia $(36 \%)$ and villous architectural abnormalities accompanied by intraepithelial lymphocytosis (37\%) [17].

\section{Other primary immunodeficiency disorders}

Less-common heritable immunodeficiency disorders may cause gastrointestinal symptoms manifesting in infancy or early childhood. Severe, recurrent diarrhea in patients with $\mathrm{X}$-linked infantile agammaglobulinemia is caused by recurrent bacterial infections or chronic giardiasis [18]. Immune dysregulation-polyendocrinopathy-X-linked syndrome is characterized by dermatitis, insulin-dependent diabetes mellitus, thyroiditis, thrombocytopenia, and hemolytic anemia accompanied by an autoimmune enteropathy and anti-enterocyte antibodies [19]. Histologic features include complete villous shortening with plasma cellrich inflammation, intraepithelial lymphocytosis, and numerous apoptotic crypt epithelial cells [20]. The syndrome is usually fatal, although bone marrow transplant may be of benefit in some cases. Severe combined immunodeficiency leads to diminished numbers, and impaired function, of B- and T cells. Patients suffer from dermatitis, diarrhea, and severe infections in infancy; they may develop functional immune systems following bone marrow transplantation [21]. 
Fig. 2 Upper endoscopy performed on a 2-year-old child with failure to thrive revealed granulomata in the duodenal submucosa a. Specimens from the jejunum showed shortened villi without increased inflammation b. Distal colon biopsy samples lacked granulomas, but revealed Paneth cell metaplasia $\mathbf{c}$ and pigmented macrophages (arrows, d).

Analysis of peripheral blood revealed impaired oxidative burst, confirming the diagnosis of chronic granulomatous disease. (Hematoxylin and eosin; original magnification: $x$ $400 \mathbf{a}, \mathbf{c} ; \times 200 \mathbf{b} ; \times 600 \mathbf{d})$

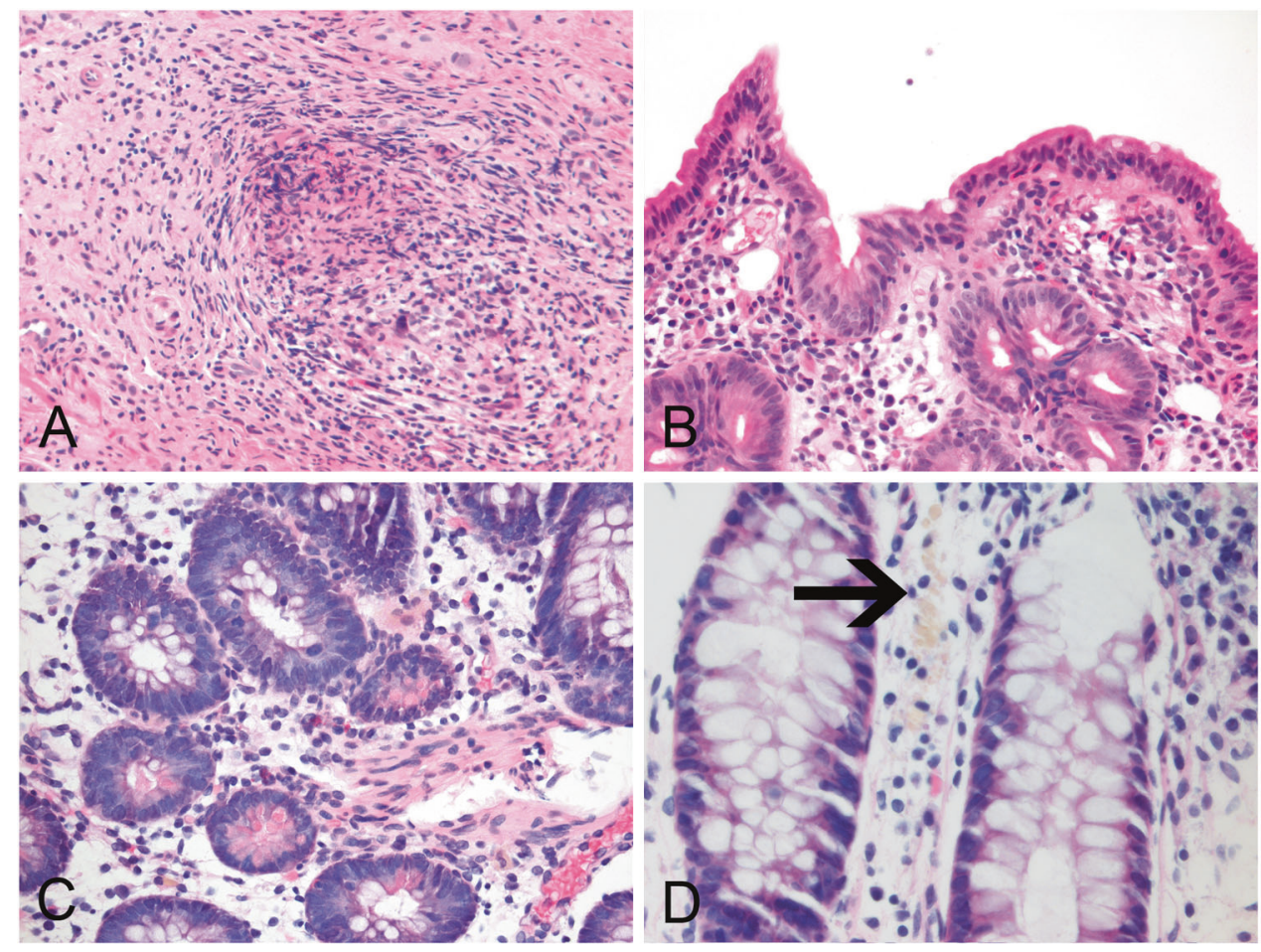

\section{Therapy-induced immunosuppression}

\section{Graft-versus-host disease}

Graft-versus-host disease complicates hematopoietic stem cell transplant in 30-70\% of allogeneic transplant recipients and $\sim 5 \%$ of autologous transplant recipients, particularly those with multiple myeloma [22]. The disease occurs when donor $\mathrm{T}$ cells recognize recipient antigens and incite an inflammatory response that damages host tissues, especially the skin, gastrointestinal tract, liver, and lungs [23]. Gastrointestinal symptoms include nausea, vomiting, anorexia, and diarrhea. Acute graft-versus-host disease is defined as occurring within the first 100 days after hematopoetic stem cell transplant, but features may persist well beyond that period, particularly if immunosuppression is withdrawn [23]. Endoscopic findings include edema, erythema, friability, erosions, and ulcers [24].

The histologic hallmark of graft-versus-host disease is prominent epithelial cell apoptosis in the regenerative compartments of the gastrointestinal epithelium (i.e., basal layers of squamous epithelium, gastric mucous neck cells, and crypt bases in the small intestine and colon) in the setting of paucicellular, mixed inflammation in the lamina propria. Apoptotic cells are often large with vacuoles containing nuclear debris, especially in colonic samples (i.e., "exploding crypt cells" or "popcorn cells"). Crypts may be cystically dilated with luminal karyorrhectic debris, and severe injury results in crypt loss, erosions, or ulcers
(Fig. 3a). Endocrine cells are somewhat resistant to injury and often appear as aggregates in the lamina propria; this feature can be a helpful clue in distinguishing graft-versushost disease from its mimics, such as mycophenolate mofetil-related injury [25]. Recent data from a large study of 116 patients with acute graft-versus-host disease suggest that loss of duodenal Paneth cells predicts a poorer response to immunosuppressive therapy [26]. Longstanding graftversus-host disease can cause crypt architectural distortion, crypt loss, lamina propria fibrosis, and Paneth cell metaplasia with minimal inflammation and rare, if any, apoptotic crypt cells. For this reason, crypt cell apoptosis is not a helpful feature when evaluating patients for possible chronic graft-versus-host disease.

Minimal diagnostic criteria for graft-versus-host disease are not well-established and inter-observer variability is problematic [27]. The Pathology Working Group of the NIH Consensus Development Project recommends examining 8-20 serial sections of each sample and requires a minimum of 1-2 apoptotic bodies per piece of biopsy tissue to establish a diagnosis of graft-versus-host disease [28]. The group also recommended that biopsy samples from patients with clinical suspicion for graft-versus-host disease be classified as (1) "not graft-versus-host disease" when diagnostic features are absent, (2) "possible graft-versushost disease" if characteristic findings are present, but other etiologies are also likely, or (3) "likely graft-versus-host disease" when competing causes are improbable based on available clinical information. Unfortunately, biopsy 
Fig. 3 The lumina of degenerating crypts contain necrotic epithelial cells in a case of graft-versus-host disease $\mathbf{a}$. Injured crypts are cystically dilated and lined by hypereosinophilic epithelial cells in a case of mycophenolate mofetil toxicity from a kidney transplant recipient $\mathbf{b}$. Nests of residual endocrine cells are more common in graft-versus-host disease $\mathbf{c}$; whereas eosinophils in the lamina propria $\mathbf{d}$ are typical of mycophenolate mofetil toxicity. (Hematoxylin and eosin; original magnification: $\times$ $400 \mathbf{a} ; \times 200 \mathbf{b}, \mathbf{d} ; \times 600 \mathbf{c})$

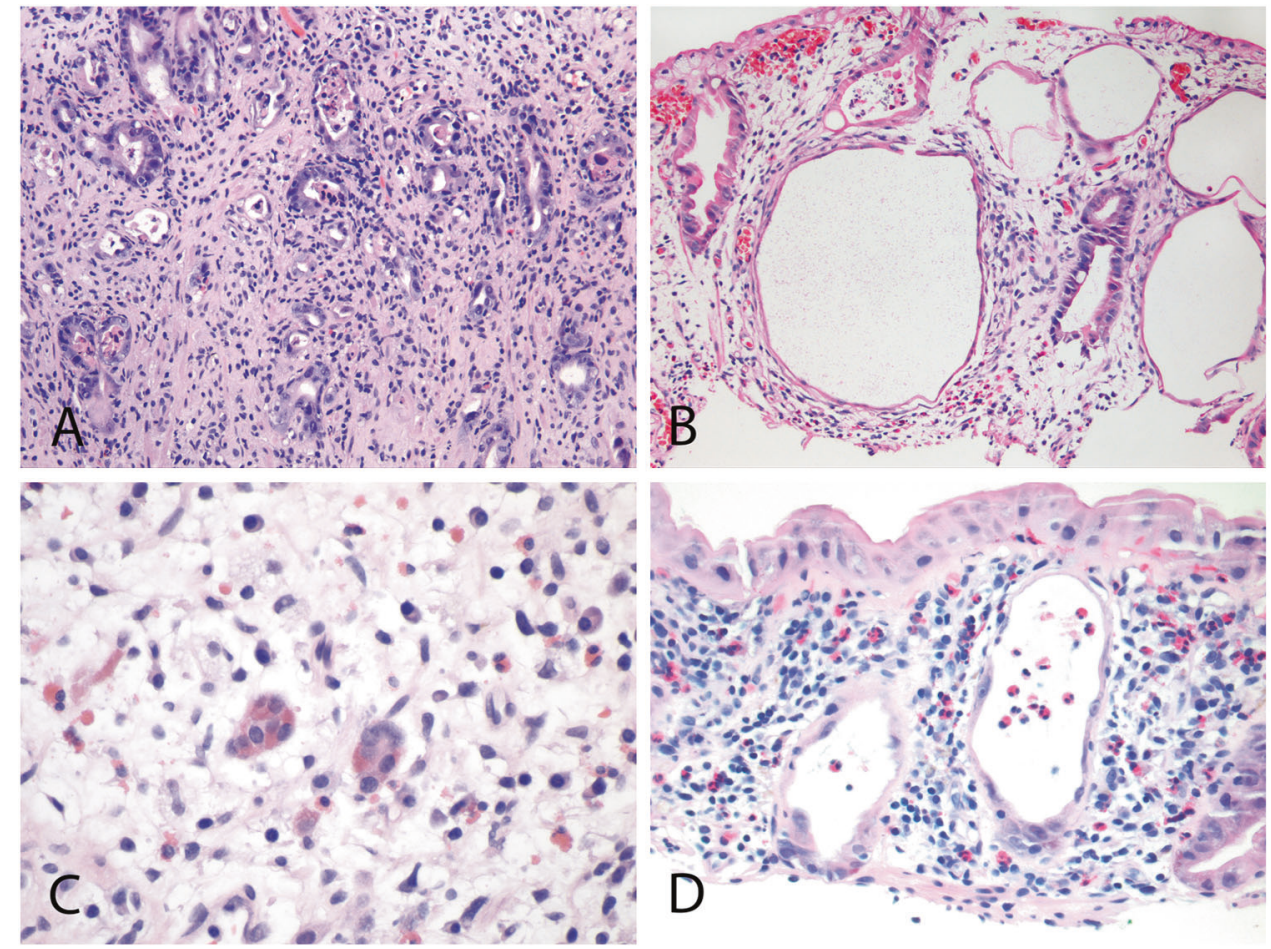

sampling may not detect graft-versus-host disease in all patients, and histologic features often show poor correlation with the endoscopic severity, although patients with severe histologic injury generally have bleeding and ulcers [29, 30].

Several authors have proposed histologic grading schemes for assessment of graft-versus-host disease, although their clinical relevance is not clearly established. Some studies show poor correlation between histologic grade and treatment response, whereas others suggest that milder histologic findings correlate with lower mortality rates [31,32]. The Lerner grading system is the most widely utilized system, but it predates modern immunosuppressive therapies, so milder cases of graft-versus-host disease tend to be grouped together as grade 1 (Table 2) [33]. Myerson et al. [34] proposed that cases classified as grade 1 be subclassified according to the number of apoptotic bodies identified in 20 crypts in order to better inform treatment decisions, although they failed to show that their classification affected treatment response. We do not grade graftversus-host disease in our practices unless severe features (i.e., mucosal denudation or ulcers) are present.

Distinguishing graft-versus-host disease from its mimics is clinically important, but often challenging (Table 3). Samples obtained within 20 days after bone marrow ablation show diffuse epithelial cell apoptosis indistinguishable from graft-versus-host disease, and thus, a definitive diagnosis of graft-versus-host disease cannot be made in the immediate post-transplant period [35]. Mycophenolate
Table 2 Classification of acute intestinal graft-versus-host disease [33]

\begin{tabular}{ll}
\hline Grade & Histologic criteria \\
\hline Grade 0 & Normal mucosa \\
Grade 1 & Apoptotic epithelial cells \\
Grade 2 & Crypt or gland destruction \\
Grade 3 & Focally denuded or ulcerated mucosa \\
Grade 4 & Diffusely denuded or ulcerated mucosa \\
\hline
\end{tabular}

mofetil suppresses B- and T-cell proliferation by inhibiting guanine synthesis, and is commonly used to prevent graft rejection in stem cell and solid organ transplant recipients [36]. This agent often causes gastrointestinal toxicity accompanied by crypt cell apoptosis, crypt loss, and variable crypt architectural distortion that simulate the features of graft-versus-host disease (Fig. 3b). Star et al. evaluated colonic biopsy samples from 17 patients with mycophenolate-related injury and 40 with graft-versus-host disease; they found that mycophenolate-related toxicity was associated with increased numbers of lamina propria eosinophils, whereas endocrine cell nests, hypereosinophilic crypt epithelial cells, and apoptotic luminal debris were significantly more common among patients with graftversus-host disease (Fig. 3c). In fact, the combination of $>15$ eosinophils per ten $\times 400$ fields (Fig. 3d) and lack of endocrine cell aggregates predicted mycophenolateassociated colitis with $76 \%$ sensitivity and $93 \%$ specificity 


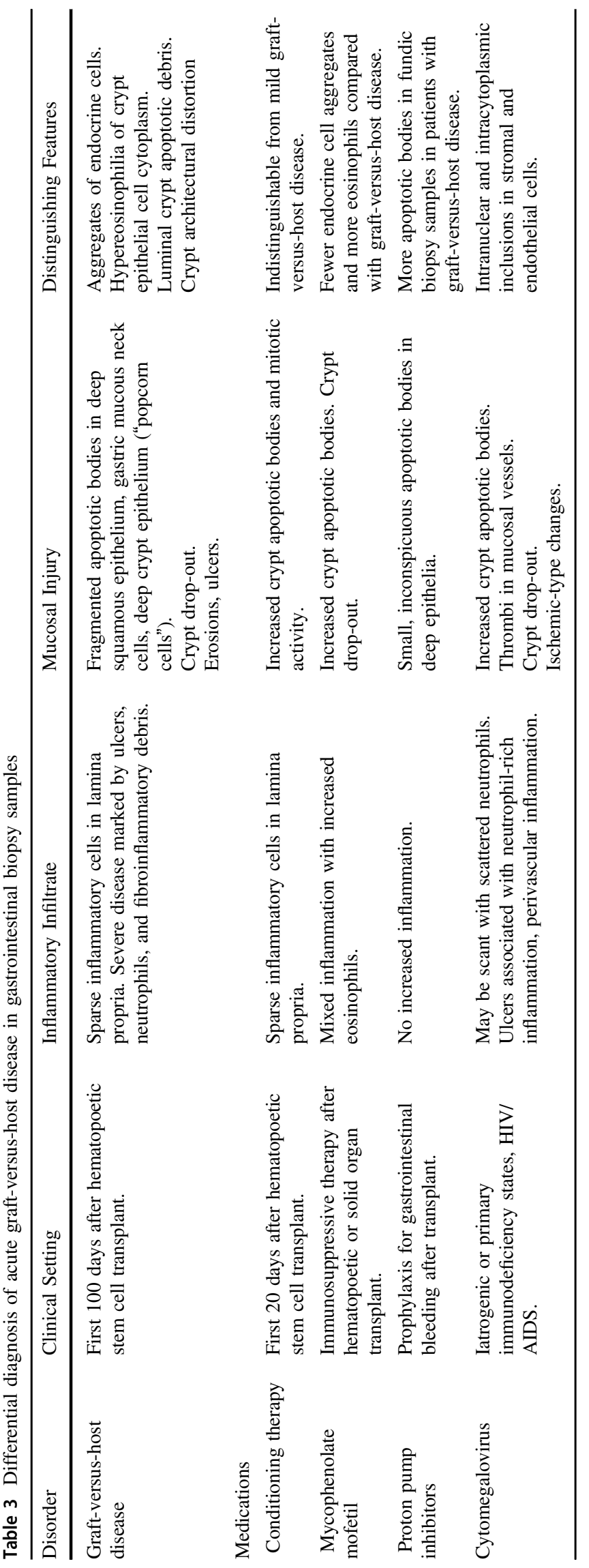

among 22 stem cell transplant recipients who were taking the drug [37].

Stem cell transplant recipients often take proton pump inhibitors in the early post-transplant period. Proton pump inhibitors induce apoptosis in gastric epithelial cells, producing overlap with graft-versus-host disease. On the other hand, gastric epithelial apoptotic bodies in graft-versus-host disease tend to be small and inconspicuous and are not easily distinguished from medication-induced injury. Welch et al. [38] analyzed gastric biopsy samples from 40 stem cell transplant recipients taking proton pump inhibitors and 32 patients who received proton pump inhibitors for other indications. Antral samples from both groups contained a mean of two apoptotic bodies per ten $\times 400$ fields, but more apoptotic bodies were present in fundic mucosa in the study group ( 3.5 versus 0.57 per ten $\times 400$ fields).

\section{Cord colitis syndrome}

Cord colitis syndrome previously described antibiotic responsive, culture-negative diarrhea of unknown etiology that developed in patients who received umbilical cord blood as an alternative to hematopoietic stem cell transplant [39]. Histologic features included chronic, variably active inflammation affecting the upper and/or lower gastrointestinal tract, accompanied by frequent granulomata. We now know that these features are neither sensitive no specific for cord colitis and are likely related to infections that, until recently, went largely undetected. Shimoji et al. [40] reviewed colonic biopsies from 49 transplant recipients, including 10 who received cord blood transplants, 25 with bone marrow transplants, and 14 with peripheral blood stem cell transplants. Histologic features were comparable regardless of the nature of the transplant; chronic active colitis was seen in all groups $(40,28$, and $29 \%$, respectively), and was also seen in biopsy samples from patients with confirmed graft-versus-host disease (36\%) and CMVassociated colitis (67\%). Most recently, Bradyrhizobium enterica was identified through DNA sequencing of tissue samples from four patients at a single institution, and other bacteria have been subsequently isolated from patients who meet clinical criteria for cord colitis syndrome [41, 42]. Thus, "cord colitis syndrome" most likely represents a nonspecific pattern of injury resulting from a variety of infections that are difficult to detect using routine testing methods.

\section{Neutropenic enterocolitis}

Neutropenic enterocolitis (i.e., typhlitis) is a type of intestinal necrosis that develops in the terminal ileum and ascending colon of neutropenic patients, particularly those who receive chemotherapy for hematologic malignancies 
Fig. 4 A right hemicolectomy from a neutropenic patient shows patchy necrosis and hemorrhage with extensive mucosal pneumatosis (arrow) a. The mucosa shows ischemictype injury with "withered" crypts and hyalinized lamina propria. Bacterial colonies are present at the surface $\mathbf{b}$ (Hematoxylin and eosin; original magnification: $\times 40$ a; $\times 400$ b)
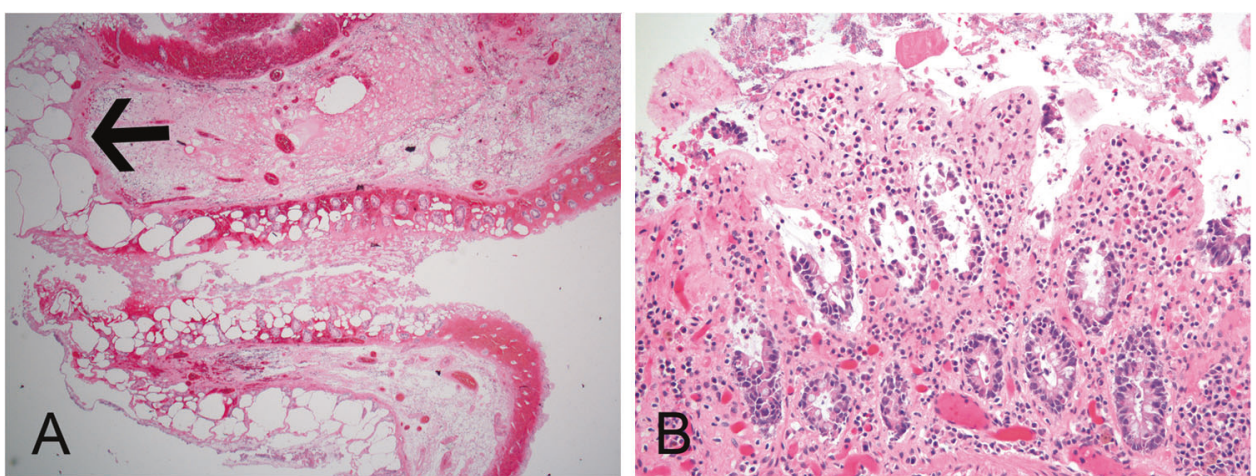

$[43,44]$. Presumably, the combination of cytotoxic druginduced cellular damage and immunosuppression affects the mucosal barrier and allows pathogens such as Klebsiella pneumonia, Escherichia coli, Enterobacter spp., Staphylococcus aureus, Streptococcus viridans, Clostridium and Candida spp., to invade the bowel wall, leading to mural necrosis [43]. Clostridium septicum, a spore-forming, gasproducing gram-positive bacterium, may cause neutropenic enterocolitis and necrotizing fasciitis in patients with gastrointestinal malignancies [45]. Patients typically present with rapidly progressive abdominal symptoms, and may develop intestinal perforations that results in death. Resection specimens show extensive ulcers with hemorrhagic necrosis and edema unaccompanied by a neutrophilic inflammatory response (Fig. 4). Gram and GMS (Gomori Methenamine Silver) stains may highlight invasive bacteria and fungi in some cases.

\section{Infectious disorders in immunocompromised patients}

\section{HIV and AIDS}

Patients with human immunodeficiency virus (HIV) may develop unexplained, culture-negative diarrhea with minimal endoscopic features as well as small bowel biopsy samples that show variable villous blunting, crypt hyperplasia, and apoptosis accompanied by mild intraepithelial lymphocytosis [46]. The disorder, termed "HIV enterocolopathy", has been attributed to the effects of HIV on enterocytes and altered mucosal immunity, although rotavirus, adenovirus, astrovirus, and picobirnavirus, have been detected in stool specimens of affected patients [47-49]. Notably, changes described in HIV enterocolopathy can be seen in asymptomatic patients with HIV infection, and some patients with diarrhea have histologically normal mucosa [47]. Widespread use of highly active antiretroviral therapy has reduced the incidence of HIV/AIDS (acquired immunodeficiency syndrome) enteropathy, as well as that of opportunistic infections occurring in patients with HIV/ AIDS [48].

\section{Viruses}

\section{CMV}

CMV is a member of the Herpesviridae family and a major cause of morbidity in immunosuppressed patients, but rarely causes disease in immunocompetent hosts [49]. New infection or reactivation of latent infection can affect any segment of the gastrointestinal tract. Esophagitis may present with odynophagia, whereas gastroenteritis produces severe watery, or bloody, diarrhea [50]. Infection of endothelial cells can lead to vascular necrosis and thrombosis, resulting in segmental ischemia [51]. Mucosal erythema, friability, and ulcers occur throughout the gastrointestinal tract. Esophageal ulcers are more common distally and usually have discrete borders, but they can be confluent and span up to $10 \mathrm{~cm}$ [52]. CMV rarely elicits an exuberant inflammatory reaction that simulates malignancy [53].

CMV infection is associated with variable inflammatory changes depending on the immune status of the patient. Immunosuppressed patients who have undergone stem cell transplant may mount a minimal response with mild neutrophilic inflammation accompanied by crypt cell apoptosis and regenerative crypts lined by attenuated epithelium, whereas plasma cell-rich inflammatory infiltrates are more common among patients with idiopathic inflammatory bowel disease who develop CMV infection as a result of corticosteroid therapy. Mucosal ulcers are associated with intravascular fibrin thrombi, activated endothelial cells, and prominent neutrophils around blood vessels. Viral cytopathic effects include nucleomegaly and cytoplasmic enlargement with inclusions in the cytoplasm and/or nuclei. Inclusions are usually identified in endothelial cells, but may also be seen in stromal cells, macrophages, and glandular epithelial cells, particularly those that contain neutral mucin (Fig. 5a). Nuclear inclusions are amphophilic and surrounded by a zone of rarified chromatin, resulting in 
Fig. 5 Cytomegalovirus infection causes erosion and ulceration of the colonic mucosa. Viral inclusions are present in inflamed granulation tissue. The associated crypts contain apoptotic bodies and karyorrhectic debris a. Nuclear inclusions (arrow) are large and amphophilic, whereas cytoplasmic inclusions are bright red and granular (block arrow). Epithelial cells that harbor adenovirus inclusions appear disordered (right) at low power compared with those lining a normal villus (left). Inclusions (arrow) are amphophilic and replace the entire nucleus. (Hematoxylin and eosin; original magnification: $\times 400 \mathbf{a}, \mathbf{c} ; \times 600$ b, d)

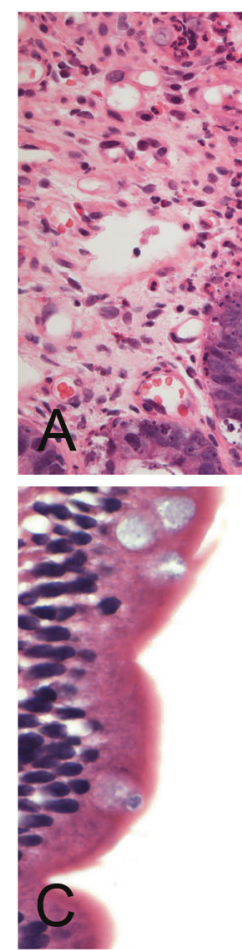

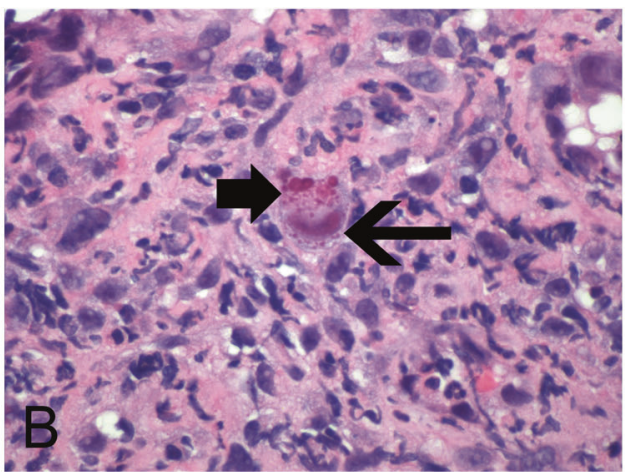
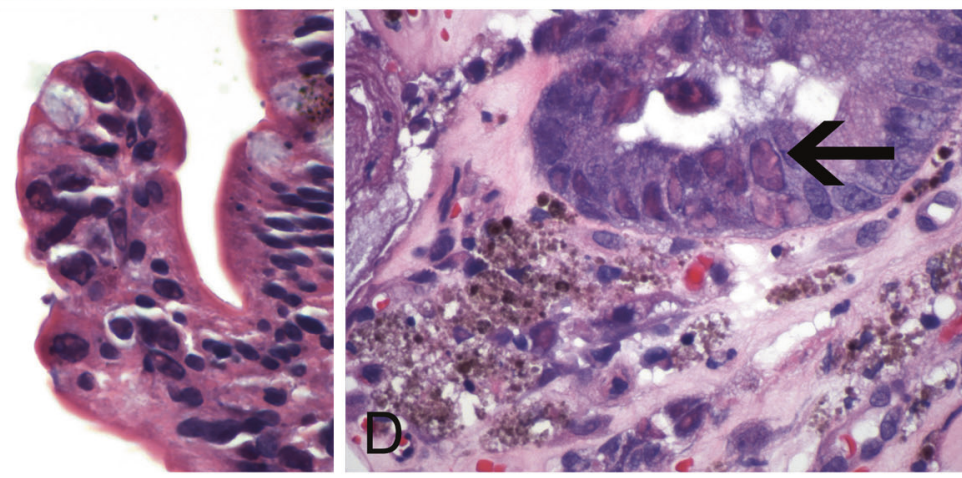

an "owl's eye" appearance, whereas cytoplasmic inclusions are granular and brightly eosinophilic (Fig. 5b).

CMV should be distinguished from other viral pathogens and disorders that commonly affect immunosuppressed patients (Tables 3 and 4) [54-57]. Viral cytopathic changes are usually apparent in routinely stained histologic sections and do not require immunohistochemistry for verification. Weidner et al. [56] performed CMV immunostains on colonic biopsy specimens from 104 hematopoietic stem cell transplant recipients and found that only two cases (2\%) contained CMV inclusions, both of which were readily detected in hematoxylin and eosin-stained sections. However, immunohistochemical stains facilitate a diagnosis when abundant inflammation and reactive cellular changes obscure characteristic features [58]. Juric-Sekhar et al. [54] evaluated 601 patients with suspected CMV based on clinical or histologic grounds; they detected viral inclusions in hematoxylin and eosin-stained sections in $2 \%$ of cases, compared with a $6 \%$ detection rate using CMV immunohistochemistry. Importantly, all CMV-positive cases showed inflammatory changes in the mucosa, and all histologically normal samples were negative for CMV by immunohistochemistry. Thus, available data suggest that immunohistochemistry facilitates CMV detection in suspicious cases that lack classic viral inclusions or when exuberant inflammatory infiltrates obscure the presence of organisms. In our practice, we routinely obtain CMV immunostains when biopsy samples from corticosteroid- dependent patients with inflammatory bowel disease show ulcers with diffuse inflammation.

Although data are limited, immunohistochemical detection of rare CMV-positive cells is probably important enough to warrant a search for virally infected cells in the appropriate clinical setting. Yan et al. [59] reported that $63 \%$ of patients with gastrointestinal complaints and isolated CMV inclusions detected by immunohistochemistry experienced symptomatic improvement following antiviral therapy. On the other hand, detection of occasional CMV-infected cells may not alter management, particularly when patients are already receiving viral prophylaxis [60]. In our practices, we only consider rare immunopositive cells to represent CMV infection when they show staining of morphologically consistent cells in an appropriate distribution (i.e., staining of nuclear or cytoplasmic inclusions), and correspond with findings in hematoxylin and eosin-stained sections; plasma cells and granulocytes can show non-specific staining with this marker. Detection of CMV DNA in paraffin-embedded tissue via polymerase chain reaction is a sensitive method for detecting the organism, but is not routinely used in current practice [61, 62].

\section{Adenovirus}

There are $>50$ adenovirus serotypes that infect human tissues, some of which show tropism for gastrointestinal mucosae [63]. Acute infection is self-limited in immunocompetent adults, but persistent, asymptomatic infection 


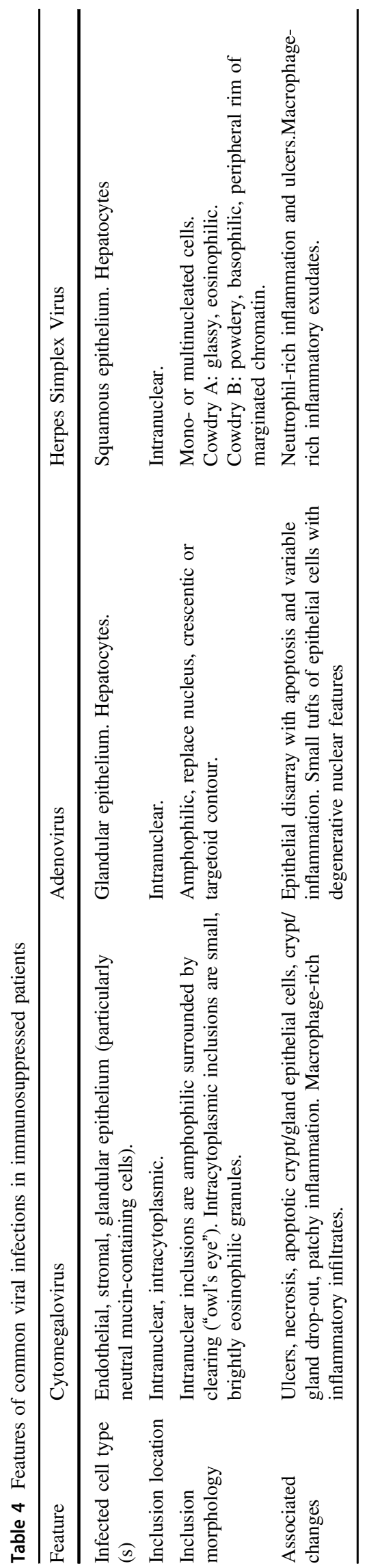

occurs in some cases [64]. Immunosuppressed individuals may develop enterocolitis, nephritis, hepatitis, pneumonia, and encephalitis, any of which may be fatal [65]. Endoscopy may reveal normal mucosa, mild erythema, or friable and granular mucosa. Biopsy samples usually show only mild changes with slightly tufted epithelium and scattered apoptotic bodies. Clusters of infected epithelial cells contain smudgy, amphophilic inclusions that impart an angulated or crescentic appearance to the nuclei. These histologic features tend to be patchy and can be readily overlooked [60]. Thus, routine use of adenovirus immunohistochemistry may be warranted when immunosuppressed patients have unexplained gastrointestinal symptoms, especially when serologic studies are not available.

\section{Herpes simplex virus (HSV)}

HSV may be transmitted sexually or through any other mucous membrane contact, and affects immunocompetent and immunocompromised individuals. The esophagus and anorectum are the most common sites of gastrointestinal infection. Most esophageal disease is caused by HSV1, and HSV2 is more common in the anorectum, but both strains cause histologically identical patterns of infection at either site [66]. Patients with herpetic esophagitis present with odynophagia, whereas anorectal disease is associated with pain and systemic symptoms including fever, lymphadenopathy, and parasthesias. Herpetic ulcers are shallow and punched out; intact and/or ruptured perianal vesicles and diffuse proctitis can be seen in patients with anorectal involvement [67].

Viral inclusions are best identified in sloughed squamous epithelium or in squamous cells at the ulcer edges. Acidophilic Cowdry A inclusions are surrounded by a halo of chromatin clearing, whereas Cowdry B inclusions are homogeneous and powdery blue. Infected cells are often multinucleated with nuclear molding (Fig. 6). The differential diagnosis includes varicella zoster virus, which can produce life-threatening infection in immunocompromised patients and displays histologically indistinguishable viral cytopathic changes. Fortunately, immunohistochemical stains directed against varicella zoster virus glycoproteins are highly sensitive and specific [55]. Multinucleated squamous cells can also be seen in patients with gastroesophageal reflux disease and other types of esophagitis; they lack nuclear molding and characteristic viral inclusions [68].

\section{Bacteria}

\section{Mycobacteria}

Intestinal tuberculosis usually results from primary infection with Mycobacterium tuberculosis or hematogenous 
Fig. 6 Biopsy samples from an anal ulcer reveal multinucleated squamous epithelial cells with marginated chromatin and nuclear inclusions typical of Herpes Simplex Virus a. Immunostains are confirmatory and can help distinguish HSV from VZV infection $\mathbf{b}$.

(Hematoxylin and eosin a HSV immunostain $\mathbf{b}$; original magnification: $\times 400$ a, b)
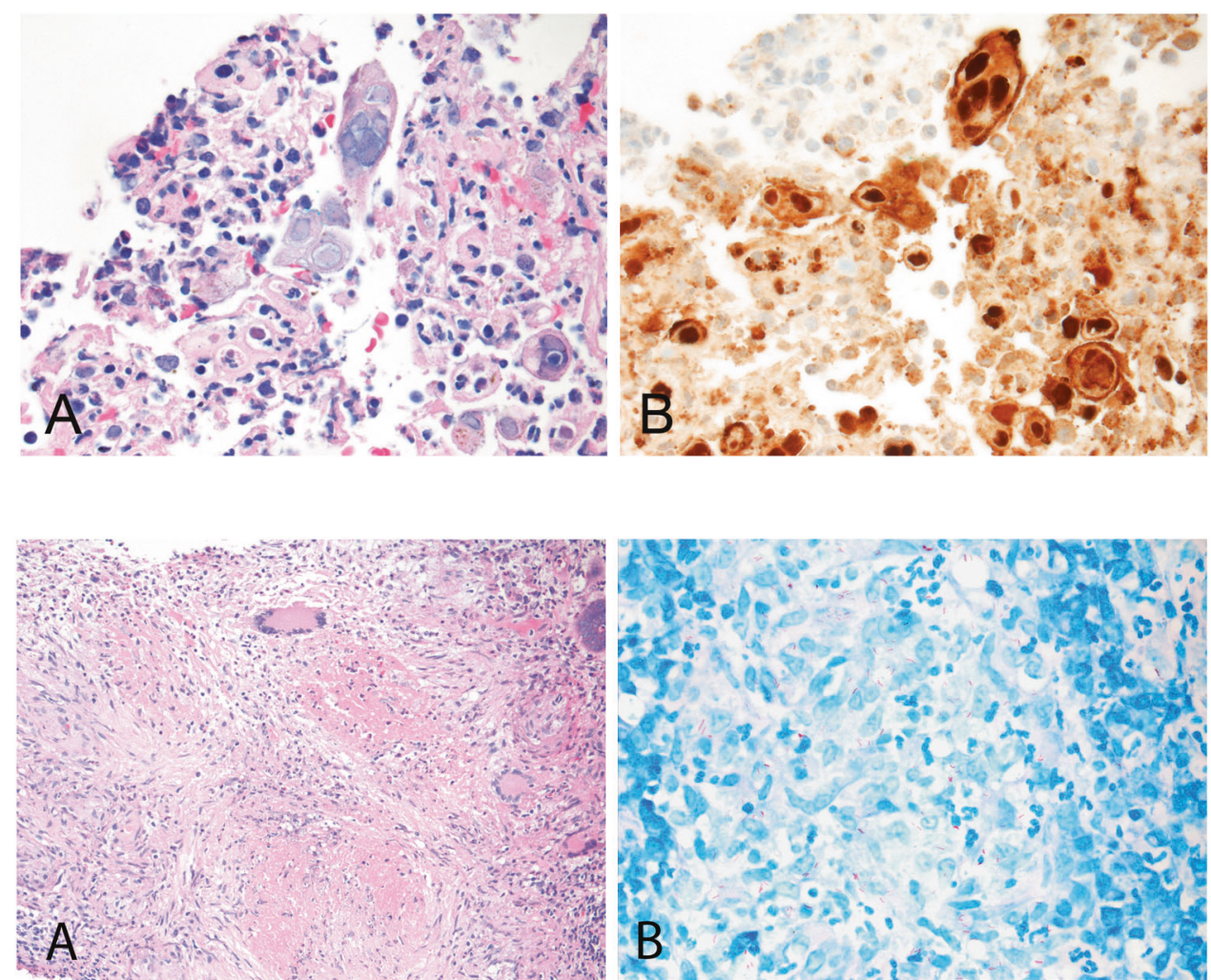
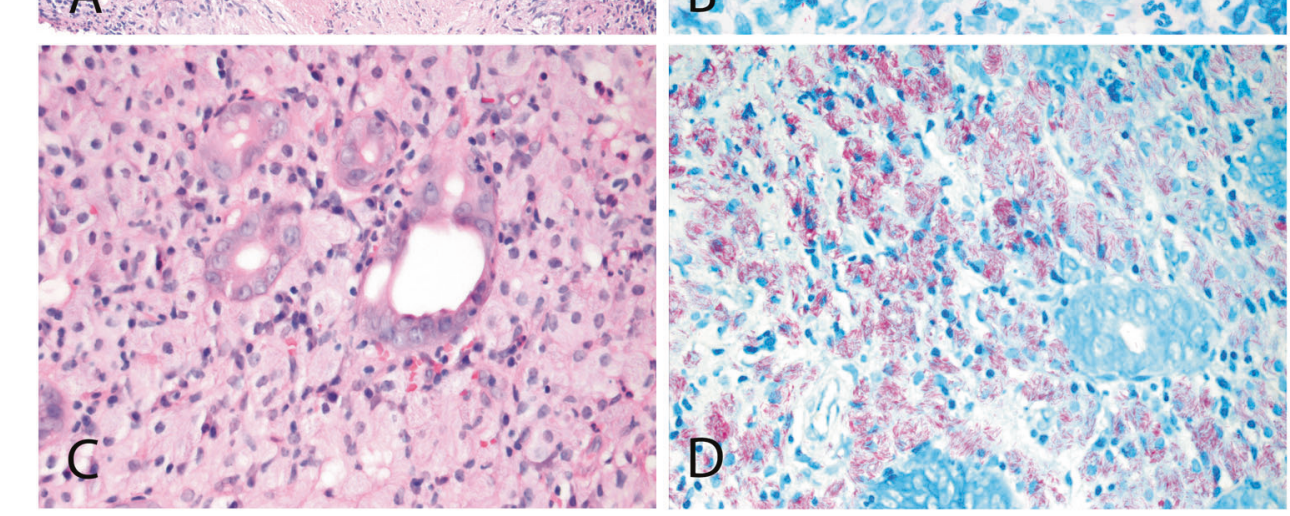

Fig. 7 This patient presented with right lower quadrant pain and a mass on physical examination. Biopsy samples from an ileocecal valve mass revealed confluent, centrally necrotic granulomata in the submucosa a. A histochemical stain for acid fast bacilli (AFB) demonstrates numerous curved rods, consistent with $M$.

tuberculosis b. A patient with AIDS underwent upper endoscopy for evaluation of abdominal pain and diarrhea. Biopsy specimens from the duodenum show macrophages filling the lamina propria $\mathbf{c}$. Intracellular bacilli, consistent with MAI, are seen on a Ziehl-Neelsen stain $\mathbf{d}$. (Hematoxylin and eosin a, c Ziehl-Neelsen stain b, d; original magnification: $\times 200 \mathbf{a}$; $\times 600 \mathbf{b} ; \times 400 \mathbf{c}, \mathbf{d})$ spread of M. tuberculosis from a pulmonary focus, although zoonotic disease due to $M$. bovis occurs following ingestion of unpasteurized milk [69]. The ileocecal region is most commonly affected because Peyer patches provide a route for bacterial entry. Intestinal tuberculosis presents with abdominal pain, fevers, night sweats, and a mass in the right lower quadrant, often in combination with mesenteric lymphadenopathy. Endoscopic features include ulcers, strictures, fistulae, inflammatory masses, and pseudopolyps [70]. Biopsy and resection specimens show chronic active ileocolitis with ulcers and mononuclear cell-rich inflammation. Epithelioid granulomata may be singly dispersed, or confluent with central necrosis and a peripheral rim of lymphocytes (Fig. 7a). Detection of organisms requires ancillary techniques (Fig. 7b) [71]. Acid fast stains, such as Ziehl-Neelsen and Fite stains, show low sensitivity owing to the paucity of bacilli in tissue sections, although the latter may improve detection of some atypical mycobacteria [72]. Immunohistochemical stains and polymerase chain reaction-based assays improve specificity over histochemical stains, but may show low sensitivity when organisms are scarce [73]. Cultures remain the gold standard for establishing a diagnosis, although they take several weeks to grow and may not be obtained in every case, particularly when the diagnosis is not suspected.

The differential diagnosis of intestinal tuberculosis includes other infectious causes of granulomatous ileocolitis, particularly Mycobacterium avium-intracellulare complex and yersiniosis, although the latter usually produces suppurative, rather than necrotic granulomata. Polymerase chain reaction-based studies that identify these infections in paraffin-embedded tissue are available [74, 75]. Distinguishing intestinal tuberculosis from Crohn disease is particularly challenging, especially in areas where $M$. 


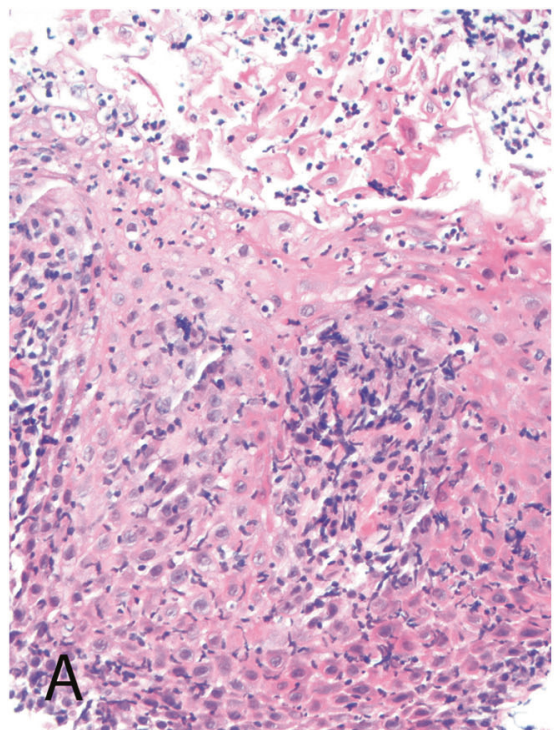

Fig. 8 The esophageal mucosa shows dense lymphocyte and neutrophil-rich inflammation in a patient with Candida infection a. Yeast and pseudohyphae are present among sloughed squamous

tuberculosis is endemic. Kirsch et al. [70] examined biopsy specimens from 18 patients with intestinal tuberculosis and 25 with Crohn disease. They reported that granulomata were more frequent in patients with tuberculosis compared with Crohn disease (78 versus 28\%), and were more numerous in the former than the latter $(2.85$ versus 0.6 per biopsy site). In that study, $67 \%$ of patients with tuberculosis had granulomata that exceeded $0.05 \mathrm{~mm}^{2}$ compared with only $8 \%$ of patients with Crohn disease. Confluent and centrally necrotic granulomata were present in 50 and $22 \%$ of tuberculosis cases, respectively, but absent in Crohn disease. Finally, Crohn disease and tuberculosis may coexist, especially in patients who are treated with TNF- $\alpha$ inhibitors because they are at risk for reactivation of latent M. tuberculosis infection [76].

Mycobacterium avium-intracellulare complex is associated with high mortality rates among patients with AIDS [77]. Infection most often involves the duodenum followed by the rectum, producing yellow nodules corresponding to macrophage aggregates in the lamina propria [78]. Infected immunocompetent patients can mount an inflammatory response marked by well-formed, occasionally necrotic granulomas that contain scant organisms, whereas bacilli-stuffed macrophages expand the lamina propria in immunocompromised patients, often effacing the villous architecture (Fig. 7c). Organisms impart a striated appearance to infected macrophages, which appear pale blue in H\&E-stained sections. They stain with acid fast (Fig. 7d) and PAS-D [79]. The differential diagnosis includes Tropheryma whipplei, the causative agent of Whipple disease [80]. These bacilli are PAS-D positive, but acid fast-negative.

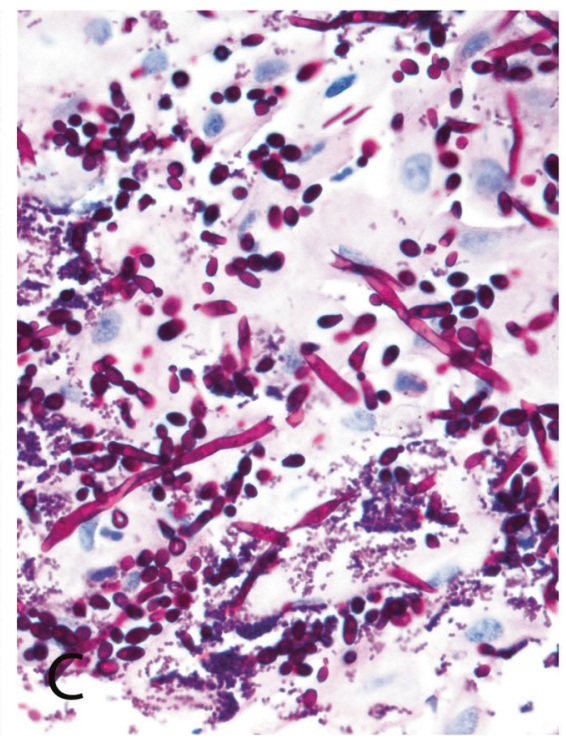

epithelial cells $\mathbf{b}$. The organisms are highlighted by a PAS-D stain $\mathbf{c}$. (Hematoxylin and eosin $\mathbf{a}, \mathbf{b}$ PAS-D stain $\mathbf{c}$; original magnification: $\times$ $200 \mathbf{a} ; \times 600 \mathbf{b}, \mathbf{c})$

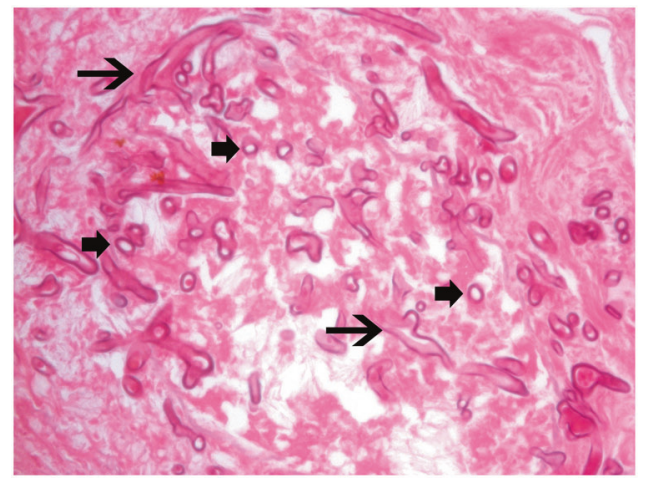

Fig. 9 Mucormycosis caused this gastric infarction. Hyphae within necrotic tissue branch at irregular angles (arrows) and appear clear when sectioned transversely (block arrows) (Hematoxylin and eosin; original magnification $\times 600$ )

\section{Fungi}

Candida spp., particularly C. albicans, are major pathogens in humans. Both $C$. tropicalis and $C$. (torulopsis) glabrata produce similar infections, although the latter occur in yeast form only. The gastrointestinal tract is the main reservoir for Candida spp.; intestinal and disseminated infections occur in the setting of altered mucosal immunity [81]. Indeed, $C$. albicans is a common cause of esophagitis, producing white plaques that bleed when disrupted. Biopsy samples show lymphocyte and neutrophil-rich inflammatory infiltrates with parakeratosis and sloughed keratin debris (Fig. 8a). Yeasts and pseudohyphae are found among sloughed keratin and epithelial cells; the latter are often oriented perpendicular to the long axes of keratinocytes in a "shish kabob" configuration (Fig. 8b,c) [82]. 
Fig. 10 A biopsy sample from an ascending colon ulcer shows yeast forms surrounded by clear "halos" within lamina propria macrophages in a case of $H$. capsulatum infection a. A PASD stain highlights the organisms b. (Hematoxylin and eosin a PAS-D stain $\mathbf{b}$; original magnification: $\times 400 \mathbf{a} ; \times 600$ b)

Fig. 11 A cluster of Giardia trophozoites is inconspicuous at the surface of uninflamed small intestinal mucosa a. The characteristic pear shape and flagella are clearly seen in a cytospin preparation from the formalin fixative of a biopsy sample b. (Hematoxylin and eosin; original magnification: $\times$ 4000a; cytospin preparation, $\times$ 600b)
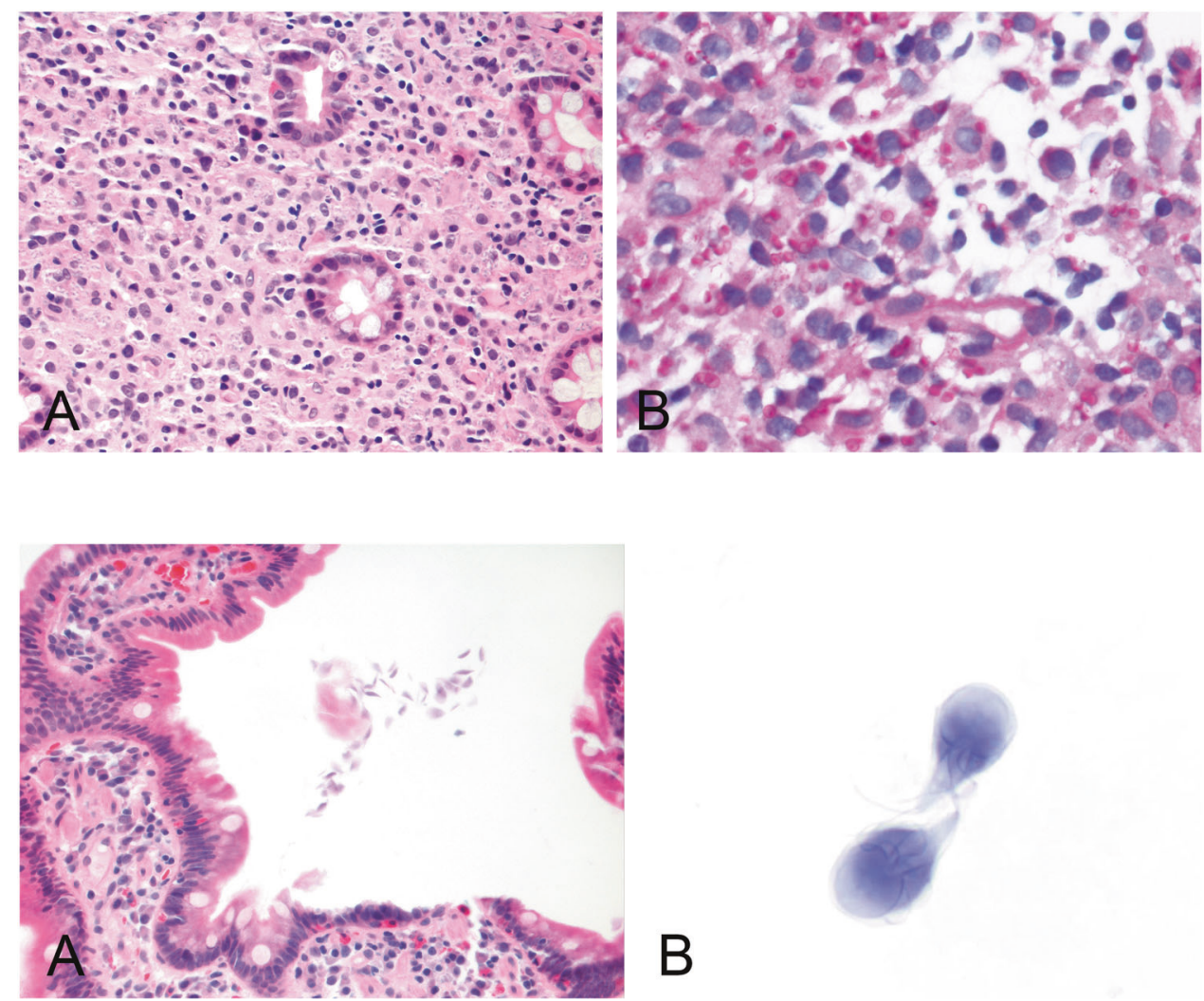

\section{Filamentous fungi}

Aspergillus spp. are ubiquitous in the environment, but rarely cause infection outside of the immunocompromised population. Aspergillus fumigatus is the most commonly isolated species, followed by A. flavus, A. terreus, and A. niger [83]. High-risk patients have prolonged neutropenia and acquire infection by inhaling spores that ultimately disseminate hematogenously to the intestinal tract. Although intestinal disease is rare, it proves fatal in up to half of cases [84]. Aspergillus spp. are angioinvasive fungi that cause vascular thrombosis and nodular mural infarction; intravascular hyphae are arranged in radial arrays and emanate into surrounding tissue. The hyphae are septate with parallel walls, and branch at $45^{\circ}$ angles. Like all fungi, they may be highlighted by GMS and PAS-D stains.

Mucormycosis causes severe infection in immunocompromised patients, particularly those with diabetes, leukemia, or lymphoma, and patients who have undergone bone marrow transplant. Organisms usually cause sinus and lung infections; only $2-10 \%$ of patients experience intestinal complications, but mortality rates approach 50\% among affected patients [85]. These fungi are also angioinvasive and cause a pattern of intestinal ischemia similar to Aspergillus spp. Hyphae are irregular with ribbon-like folds and central clearing; they are pauciseptate and branch at random angles (Fig. 9).
Yeast

Histoplasma capsulatum is commonly found in bird and bat droppings and is endemic to the Mississippi and Ohio River valleys, Mexico, and regions of Central and South America [86]. It exists in a filamentous mold form in its natural environment, but assumes a yeast form in warm-blooded hosts. Immunocompetent patients are usually asymptomatic, but may harbor non-viable organisms within granulomata [87]. However, spores disseminate to the spleen, bone marrow, gastrointestinal tract, and liver in immunocompromised individuals, particularly those with HIV/ AIDS [88]. The yeast are ovoid, measure 2-4 $\mu \mathrm{m}$, and show narrow-based budding surrounded by a "halo" of rarified cytoplasm (Fig. 10). Yeast-bearing macrophages rarely form epithelioid granulomata. Rather, they fill and distend the lamina propria of the small intestine, causing effacement of the villous architecture.

Penicillium marneffei can cause severe infection in the immunocompromised population. This dimorphic fungus is endemic to China and Southeast Asia [89]. Disseminated infection occurs in immunocompromised patients, particularly those with AIDS, and pursues an aggressive, often fatal course. Endoscopic findings include erosions, ulcers, and masses that simulate malignancy [90]. Yeast accumulate in macrophages, are ovoid, and span 2-5 $\mu \mathrm{m}$, similar to Histoplasma capsulatum. Some organisms are much larger with curved ends [91]. 
Cryptococcus neoformans causes suppurative and necrotizing gastrointestinal disease among immunosuppressed patients with disseminated infection [92]. Any site in the gastrointestinal tract may be affected. Ovoid yeasts are extracellular, span 4-7 $\mu \mathrm{m}$, and have a mucopolysaccharide capsule that is clear and colorless in H\&Estained sections [93]. The capsule stains magenta with mucicarmine, although capsule-deficient strains are mucicarmine-negative [94].

\section{Protozoans}

Giardia lamblia is spread via fecal-oral transmission and contaminated water and food [95]. It causes a self-limited illness in immunocompetent individuals, but patients with HIV/AIDS, selective IgA deficiency, and common variable immunodeficiency are at risk for recurrent, or prolonged, infection owing to impaired mucosal immunity [96]. The organism usually completes its lifecycle in the proximal small intestine, but may be detected in the ileum in rare cases [97]. Pear-shaped, or crescentic, trophozoites reside in the intervillous spaces near the luminal epithelium and are flagellated with two nuclei and a central karyosome (Fig. 11a). They are easily overlooked because colonization elicits no, or minimal, inflammatory changes in duodenal biopsy samples [98]. Robertson et al. [99] retrospectively reviewed biopsy specimens from 40 patients with positive stool studies and found that only eight (20\%) had organisms in duodenal biopsies, including three $(38 \%)$ in which the organisms were not prospectively identified. Organism morphology is best appreciated in cytology samples; cytospin preparations obtained from the formalin fixative of duodenal biopsies contain more numerous, better preserved trophozoites than histologic sections (Fig. 11b) [100].

Unicellular protozoa of the Conoidasida class are an important cause of diarrhea in tropical climates, and also cause illness among immunocompromised patients in temperate regions, particularly those with HIV/AIDS [95, 101104]. The latter are at risk for severe diarrhea with dehydration and malabsorption. Organisms are typically transmitted through contaminated water sources. Most affected patients have normal, or near normal, endoscopic examinations associated with mild inflammatory changes in mucosal samples, including patchy intraepithelial lymphocytosis, scattered apoptotic epithelial cell debris, and occasional neutrophils. Cryptosporidia parvum, C. hominis, $C$ meleagridis, Cyclospora cayetanensis, and Cystisospora belli, and Microsporidia have been historically classified as coccidians, although results of recent molecular data have led to substantial reclassification. Cryptosporidia are now classified as gregarines, a subclass of Conoidasida closely related to coccidians (Fig. 12a) [102]. C. belli (formerly Isospora belli) (Fig. 12b) and C. cayatenensis (Fig. 12c) are

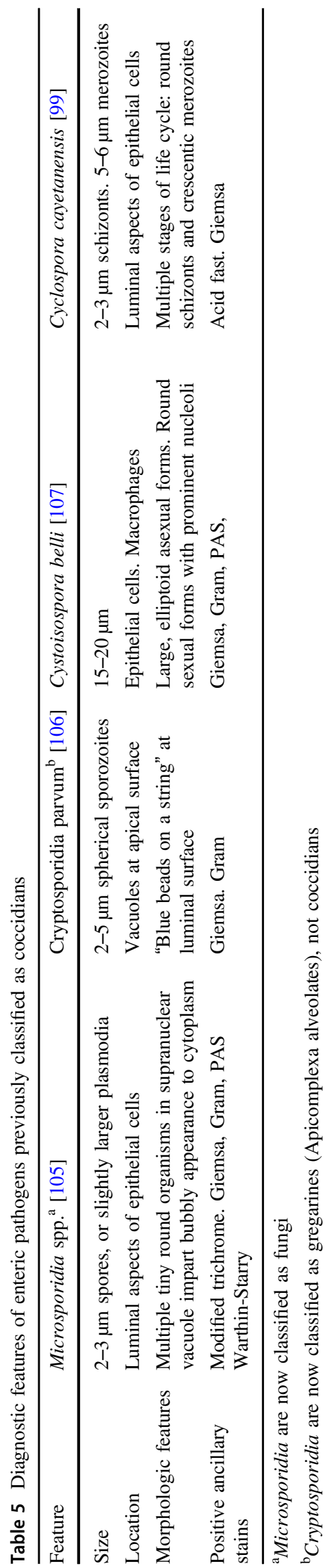


Fig. 12 Cryptosporidium parvum appear as round basophilic dots (arrow) at the apices of epithelial cells in a colonic crypt a. Cystoisospora belli are round (arrow) or elongated (block arrow) and are present in large parasitophorous vacuoles, Courtesy Joel K. Greenson, MD b. Round sexual (arrow) and crescentic asexual (block arrow) Cyclospora cayatenensis forms are present in the upper third of epithelial cells c. Microsporidia spores (arrows) are barely perceptible in routine sections; vacuolated cytoplasm is a clue to the diagnosis $\mathbf{d}$ (Hematoxylin and eosin; original magnification: $x$ $600 \mathbf{a}, \mathbf{b} ; \times 1000$ oil immersion c; $\times 400 \mathbf{d})$

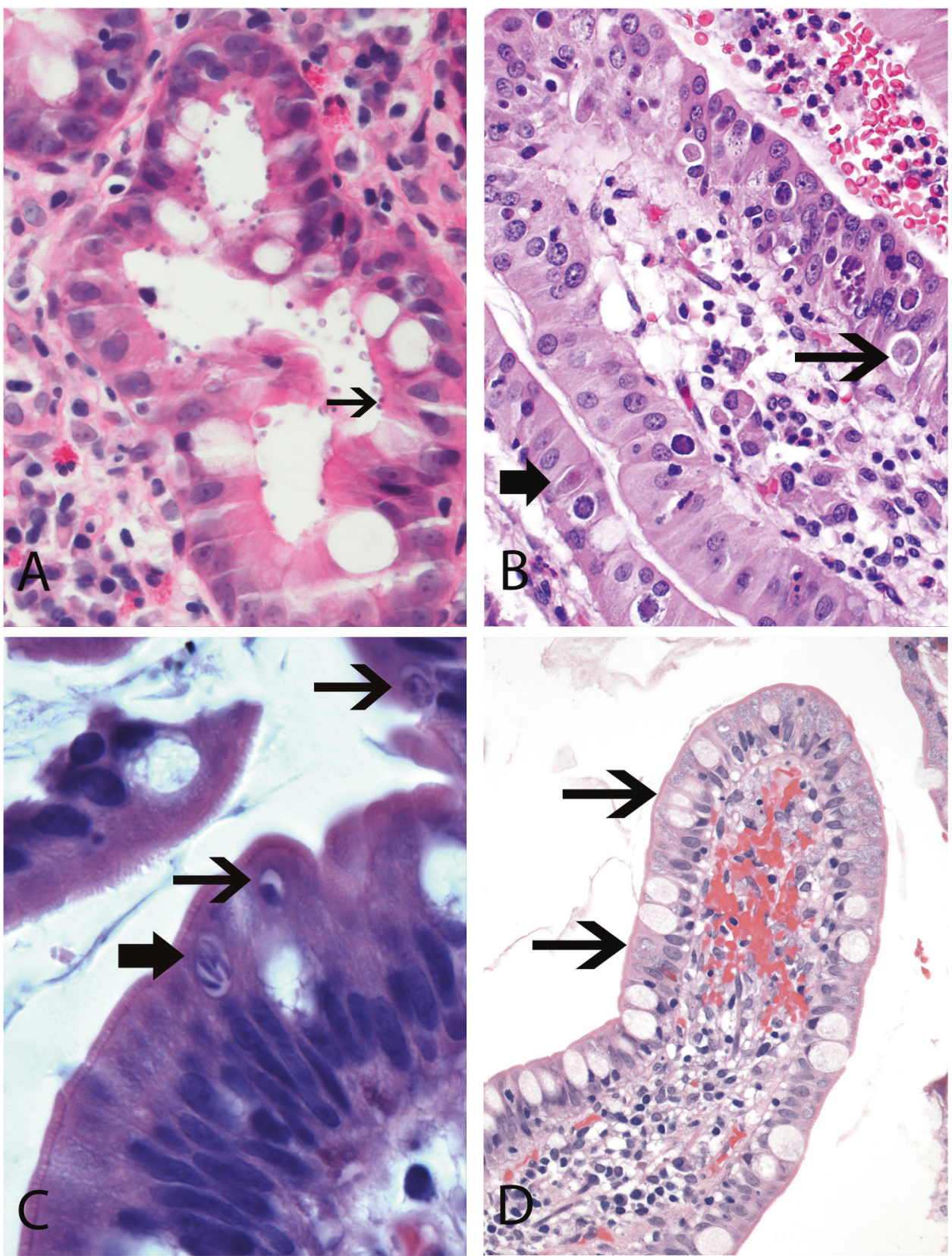

still classified as coccidians [103, 104, 95], Microsporidia was previously classified as a protozoan, but is now considered to be a fungus (Fig. 12d) [101]. Stool studies with ancillary stains and/or PCR-based assays are often used to detect organisms, although they can also be seen in H\&Estained sections (Table 5).

\section{Nematodes}

Strongyloides stercoralis is a nematode endemic to tropical and subtropical regions and the southeastern United States [105]. Immunocompromised patients with chronic corticosteroid therapy, solid organ transplantation, and human $\mathrm{T}$ lymphotrophic virus type 1 infection at increased risk for severe infection, whereas HIV/AIDS does not appear to be a significant risk factor. Of note, we have seen a few cases of chronic strongyloidiasis in patients with common variable immunodeficiency, although this relationship has not been described in the literature. Transmission occurs when filariform larvae present in soil penetrate exposed skin and ultimately migrate to the duodenum and jejunum where females mature and lay eggs that hatch into rhabtidiform larvae. These larvae can differentiate into infectious filariform larvae without excretion into the environment to complete the lifecycle. As a result, patients can be infected for decades despite the presence of only mild symptoms. 


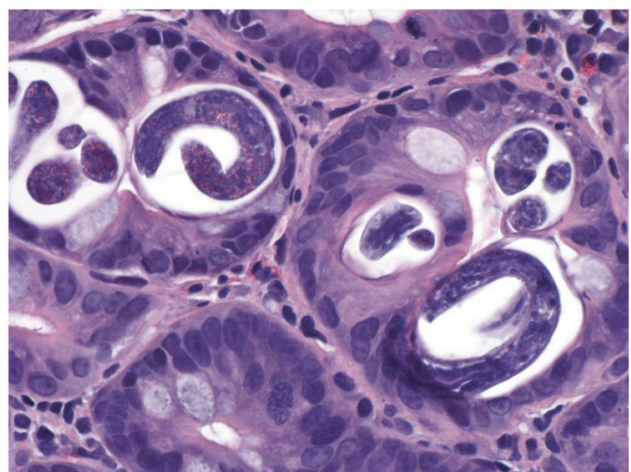

Fig. 13 Strongyloides larvae in small intestinal crypts are curved with one pointed end. (Hematoxylin and eosin; original magnification: $\times$ 400)

Hyperinfection describes a syndrome of accelerated autoinfection that occurs in immunosuppressed patients, particularly those who are co-infected with human $\mathrm{T}$ lymphotrophic virus type 1 and those receiving corticosteroids [106]. Gastrointestinal symptoms include diarrhea, vomiting, small bowel obstruction, and protein-losing enteropathy. Endoscopic and colonoscopic findings are often non-specific, but small yellow spots reflecting lymphatic obstruction by larvae raise the possibility of infection in endemic regions; ulcers, mass lesions and pseudopolyposis are also reported [107, 108].

The diagnosis of active strongyloidiasis infection is based on identification of larvae and eggs in stool or tissue, as serologic detection of Strongyloides immunoglobulins may reflect past infection [109]. Eggs, larvae, and adult worms are found throughout the gastrointestinal tract, although small intestinal biopsies have the highest yield [110]. Larvae and adult worms are present in the lamina propria and within intestinal crypts. They are curved with pointed tails and long, basophilic ova (Fig. 13). Organisms elicit eosinophil-rich inflammation when they transgress the crypt basement membrane and invade the lamina propria. Lymphoplasmacytic inflammation is often present, but generally mild. Infection may be associated with crypt and villous architectural distortion that simulate features of idiopathic inflammatory bowel disease.

\section{Summary and conclusions}

Immunocompromised patients often have gastrointestinal symptoms that can be due to the underlying immunodeficiency, or result from either a superimposed infection or drug-related injury. Pathologists have an important role in recognizing and classifying patterns of injury in biopsy samples from affected patients. Attention to subtle histologic findings, examination of multiple tissue levels and/or ancillary stains, and correlation with clinical features and laboratory studies facilitate a diagnosis in these challenging cases.

Acknowledgements We thank Laura W. Lamps, MD for her critical review of this manuscript.

Conflict of interest The authors declare that they have no conflict of interest.

\section{References}

1. Conley ME, Notarangelo LD, Etzioni A. Diagnostic criteria for primary immunodeficiencies. Representing PAGID (Pan-American Group for Immunodeficiency) and ESID (European Society for Immunodeficiencies). Clin Immunol. 1999;93:190-7.

2. Bonilla FA, Barlan I, Chapel H, et al. International Consensus Document (ICON): common variable immunodeficiency disorders. J Allergy Clin Immunol Pract. 2016;4:38-59.

3. Patuzzo G, Barbieri A, Tinazzi E, et al. Autoimmunity and infection in common variable immunodeficiency (CVID). Autoimmun Rev. 2016;15:877-82.

4. Mortaz E, Tabarsi P, Mansouri D, et al. Cancers related to immunodeficiencies: update and perspectives. Front Immunol. 2016;7:365.

5. Malamut G, Verkarre V, Suarez F, et al. The enteropathy associated with common variable immunodeficiency: the delineated frontiers with celiac disease. Am J Gastroenterol. 2010;105:2262-75.

6. Molaei M, Kaboli A, Fathi AM, et al. Nodular lymphoid hyperplasia in common variable immunodeficiency syndrome mimicking familial adenomatous polyposis on endoscopy. Indian J Pathol Microbiol. 2009;52:530-3.

7. Biagi F, Bianchi PI, Zilli A, et al. The significance of duodenal mucosal atrophy in patients with common variable immunodeficiency: a clinical and histopathologic study. Am J Clin Pathol. 2012;138:185-9.

8. Daniels JA, Lederman HM, Maitra A, et al. Gastrointestinal tract pathology in patients with common variable immunodeficiency (CVID): a clinicopathologic study and review. Am J Surg Pathol. 2007;31:1800-12.

9. Washington K, Stenzel TT, Buckley RH, et al. Gastrointestinal pathology in patients with common variable immunodeficiency and X-linked agammaglobulinemia. Am J Surg Pathol. 1996;20:1240-52.

10. Aghamohammadi A, Cheraghi T, Gharagozlou M, et al. IgA deficiency: correlation between clinical and immunological phenotypes. J Clin Immunol. 2009;29:130-6.

11. Barton SH, Murray JA. Celiac disease and autoimmunity in the gut and elsewhere. Gastroenterol Clin North Am. 2008;37:411-28. vii

12. Pallav K, Xu H, Leffler DA, et al. Immunoglobulin A deficiency in celiac disease in the United States. J Gastroenterol Hepatol. 2016;31:133-7.

13. Lai KK, Lamps LW. Enterocolitis in immunocompromised patients. Semin Diagn Pathol. 2014;31:176-91.

14. Marciano BE, Rosenzweig SD, Kleiner DE, et al. Gastrointestinal involvement in chronic granulomatous disease. Pediatrics. 2004;114:462-8.

15. Obayashi N, Arai K, Nakano N, et al. Leopard skin-like colonic mucosa: a novel endoscopic finding of chronic granulomatous disease-associated colitis. J Pediatr Gastroenterol Nutr. 2016;62:56-59. 
16. Marks DJ, Miyagi K, Rahman FZ, et al. Inflammatory bowel disease in CGD reproduces the clinicopathological features of Crohn's disease. Am J Gastroenterol. 2009;104:117-24.

17. Alimchandani M, Lai JP, Aung PP, et al. Gastrointestinal histopathology in chronic granulomatous disease: a study of 87 patients. Am J Surg Pathol. 2013;37:1365-72.

18. Lederman HM, Winkelstein JA. X-linked agammaglobulinemia: an analysis of 96 patients. Med (Baltim). 1985;64: 145-56.

19. Chandrakasan S, Venkateswaran S, Kugathasan S. Nonclassic inflammatory bowel disease in young infants: immune dysregulation, polyendocrinopathy, enteropathy, X-linked syndrome, and other disorders. Pediatr Clin North Am. 2017;64:139-60.

20. Krones E, Hogenauer C. Diarrhea in the immunocompromised patient. Gastroenterol Clin North Am. 2012;41:677-701.

21. Heimall J, Puck J, Buckley R, et al. Current knowledge and priorities for future research in late effects after hematopoietic stem cell transplantation (HCT) for severe combined immunodeficiency patients: a consensus statement from the second pediatric blood and marrow transplant consortium international conference on late effects after pediatric HCT. Biol Blood Marrow Transplant. 2017;23:379-87.

22. Lee SJ, Flowers ME. Recognizing and managing chronic graftversus-host disease. Hematology Am Soc Hematol Educ Program. 2008;1:134-141.

23. Holtan SG, Pasquini M, Weisdorf DJ. Acute graft-versus-host disease: a bench-to-bedside update. Blood. 2014;124:363-73.

24. Ross WA, Couriel D. Colonic graft-versus-host disease. Curr Opin Gastroenterol. 2005;21:64-69.

25. Lampert IA, Thorpe P, van Noorden S, et al. Selective sparing of enterochromaffin cells in graft versus host disease affecting the colonic mucosa. Histopathology. 1985;9:875-86.

26. Levine JE, Huber E, Hammer ST, et al. Low Paneth cell numbers at onset of gastrointestinal graft-versus-host disease identify patients at high risk for nonrelapse mortality. Blood. 2013;122:1505-9.

27. Kreft A, Mottok A, Mesteri I, et al. Consensus diagnostic histopathological criteria for acute gastrointestinal graft versus host disease improve interobserver reproducibility. Virchows Arch. 2015;467:255-63.

28. Shulman HM, Cardona DM, Greenson JK, et al. NIH Consensus development project on criteria for clinical trials in chronic graftversus-host disease: II. The 2014 Pathology Working Group Report. Biol Blood Marrow Transplant. 2015;21:589-603.

29. Yeh SP, Liao YM, Hsu CH, et al. Gastric bleeding due to graftvs-host disease: discrepancy between endoscopic and histologic assessment. Am J Clin Pathol. 2004;122:919-25.

30. Cruz-Correa M, Poonawala A, Abraham SC, et al. Endoscopic findings predict the histologic diagnosis in gastrointestinal graftversus-host disease. Endoscopy. 2002;34:808-13.

31. Abraham J, Janin A, Gornet JM, et al. Clinical severity scores in gastrointestinal graft-versus-host disease. Transplantation. 2014;97:965-71.

32. Narkhede M, Rybicki L, Abounader D, et al. The association of histologic grade with acute graft-versus-host disease response and outcomes. Am J Hematol. 2017;92:683-8.

33. Lerner KG, Kao GF, Storb R, et al. Histopathology of graft-vs.host reaction (GvHR) in human recipients of marrow from HLA-matched sibling donors. Transplant Proc. 1974;6:367-71.

34. Myerson D, Steinbach G, Gooley TA, et al. Graft-versus-host disease of the gut: a histologic activity grading system and validation. Biol Blood Marrow Transplant. 2017;23:1573-9.

35. Epstein RJ, McDonald GB, Sale GE, et al. The diagnostic accuracy of the rectal biopsy in acute graft-versus-host disease: a prospective study of thirteen patients. Gastroenterology. 1980;78:764-71.
36. Kamar N, Faure P, Dupuis E, et al. Villous atrophy induced by mycophenolate mofetil in renal-transplant patients. Transpl Int. 2004; 17:463-7.

37. Star KV, Ho VT, Wang HH, et al. Histologic features in colon biopsies can discriminate mycophenolate from GVHD-induced colitis. Am J Surg Pathol. 2013;37:1319-28.

38. Welch DC, Wirth PS, Goldenring JR, et al. Gastric graft-versushost disease revisited: does proton pump inhibitor therapy affect endoscopic gastric biopsy interpretation? Am J Surg Pathol. 2006;30:444-9.

39. Herrera AF, Soriano G, Bellizzi AM, et al. Cord colitis syndrome in cord-blood stem-cell transplantation. $\mathrm{N}$ Engl $\mathrm{J}$ Med. 2011;365:815-24.

40. Shimoji S, Kato K, Eriguchi Y, et al. Evaluating the association between histological manifestations of cord colitis syndrome with GVHD. Bone Marrow Transplant. 2013;48:1249-52.

41. Bhatt AS, Freeman SS, Herrera AF, et al. Sequence-based discovery of Bradyrhizobium enterica in cord colitis syndrome. $\mathrm{N}$ Engl J Med. 2013;369:517-28.

42. Gorkiewicz G, Trajanoski S, Hogenauer C. Bradyrhizobium enterica in cord colitis syndrome. $\mathrm{N}$ Engl $\mathrm{J}$ Med. 2013;369:1866-7.

43. Machado NO. Neutropenic enterocolitis: a continuing medical and surgical challenge. N Am J Med Sci. 2010;2:293-300.

44. Sachak T, Arnold MA, Naini BV, et al. Neutropenic enterocolitis: new insights into a deadly entity. Am J Surg Pathol. 2015;39:1635-42.

45. Hermsen JL, Schurr MJ, Kudsk KA, et al. Phenotyping Clostridium septicum infection: a surgeon's infectious disease. J Surg Res. 2008;148:67-76.

46. Batman PA, Kapembwa MS, Belmonte L, et al. HIV enteropathy: HAART reduces HIV-induced stem cell hyperproliferation and crypt hypertrophy to normal in jejunal mucosa. J Clin Pathol. 2014;67:14-18.

47. Batman PA, Miller AR, Forster SM, et al. Jejunal enteropathy associated with human immunodeficiency virus infection: quantitative histology. J Clin Pathol. 1989;42:275-81.

48. Cello JP, Day LW. Idiopathic AIDS enteropathy and treatment of gastrointestinal opportunistic pathogens. Gastroenterology. 2009;136:1952-65.

49. Cannon MJ, Schmid DS, Hyde TB. Review of cytomegalovirus seroprevalence and demographic characteristics associated with infection. Rev Med Virol. 2010;20:202-13.

50. Chetty R, Roskell DE. Cytomegalovirus infection in the gastrointestinal tract. J Clin Pathol. 1994;47:968-72.

51. Keates J, Lagahee S, Crilley P, et al. CMV enteritis causing segmental ischemia and massive intestinal hemorrhage. Gastrointest Endosc. 2001;53:355-9.

52. Chen YM, Hung YP, Huang CF, et al. Cytomegalovirus disease in nonimmunocompromised, human immunodeficiency virusnegative adults with chronic kidney disease. J Microbiol Immunol Infect. 2014;47:345-9.

53. Shah R, Vaidya G, Kalakonda A, et al. Cytomegalovirus colitis mimicking rectal carcinoma in a young immunocompetent patient. ACG Case Rep J. 2015;2:165-7.

54. Juric-Sekhar G, Upton MP, Swanson PE, et al. Cytomegalovirus (CMV) in gastrointestinal mucosal biopsies: should a pathologist perform CMV immunohistochemistry if the clinician requests it? Hum Pathol. 2017;60:11-15.

55. Nikkels AF, Delvenne P, Sadzot-Delvaux C, et al. Distribution of varicella zoster virus and herpes simplex virus in disseminated fatal infections. J Clin Pathol. 1996;49:243-8.

56. Weidner AS, Panarelli NC, Rennert $\mathrm{H}$, et al. Immunohistochemistry improves the detection of adenovirus in gastrointestinal biopsy specimens from hematopoietic stem cell transplant recipients. Am J Clin Pathol. 2016;146:627-31. 
57. Solomon IH, Hornick JL, Laga AC. Immunohistochemistry is rarely justified for the diagnosis of viral infections. Am J Clin Pathol. 2017;147:96-104.

58. McCurdy JD, Enders FT, Jones A, et al. Detection of cytomegalovirus in patients with inflammatory bowel disease: where to biopsy and how many biopsies? Inflamm Bowel Dis. 2015;21:2833-8.

59. Yan Z, Wang L, Dennis J, et al. Clinical significance of isolated cytomegalovirus-infected gastrointestinal cells. Int J Surg Pathol. 2014;22:492-8

60. Solomon IH, Hornick JL, Laga AC. Immunohistochemistry is rarely justified for the diagnosis of viral infections. Am J Clin Pathol. 2016;147:96-104.

61. McCoy MH, Post K, Sen JD, et al. qPCR increases sensitivity to detect cytomegalovirus in formalin-fixed, paraffin-embedded tissue of gastrointestinal biopsies. Hum Pathol. 2014;45:48-53.

62. Mills AM, Guo FP, Copland AP, et al. A comparison of CMV detection in gastrointestinal mucosal biopsies using immunohistochemistry and PCR performed on formalin-fixed, paraffinembedded tissue. Am J Surg Pathol. 2013;37:995-1000.

63. Leen AM, Rooney CM. Adenovirus as an emerging pathogen in immunocompromised patients. $\mathrm{Br} \mathrm{J}$ Haematol. 2005;128:135-44.

64. Fox JP, Brandt CD, Wassermann FE, et al. The virus watch program: a continuing surveillance of viral infections in metropolitan New York families. VI. Observations of adenovirus infections: virus excretion patterns, antibody response, efficiency of surveillance, patterns of infections, and relation to illness. Am J Epidemiol. 1969;89:25-50.

65. Runde V, Ross S, Trenschel R, et al. Adenoviral infection after allogeneic stem cell transplantation (SCT): report on 130 patients from a single SCT unit involved in a prospective multi center surveillance study. Bone Marrow Transplant. 2001;28:51-57.

66. Workowski KA, Berman S, Centers for Disease C. et al. Sexually transmitted diseases treatment guidelines, 2010. MMWR Recomm Rep. 2010;59:1-110.

67. Goodell SE, Quinn TC, Mkrtichian E, et al. Herpes simplex virus proctitis in homosexual men. Clinical, sigmoidoscopic, and histopathological features. N Engl J Med. 1983;308:868-71.

68. Singh SP, Odze RD. Multinucleated epithelial giant cell changes in esophagitis: a clinicopathologic study of 14 cases. Am J Surg Pathol. 1998;22:93-99.

69. Donoghue HD, Holton J. Intestinal tuberculosis. Curr Opin Infect Dis. 2009;22:490-6.

70. Kirsch R, Pentecost M, Hall Pde M, et al. Role of colonoscopic biopsy in distinguishing between Crohn's disease and intestinal tuberculosis. J Clin Pathol. 2006;59:840-4.

71. Almadi MA, Ghosh S, Aljebreen AM. Differentiating intestinal tuberculosis from Crohn's disease: a diagnostic challenge. Am J Gastroenterol. 2009;104:1003-12.

72. Woods GL, Walker DH. Detection of infection or infectious agents by use of cytologic and histologic stains. Clin Microbiol Rev. 1996;9:382-404.

73. Mustafa T, Wiker HG, Mfinanga SG, et al. Immunohistochemistry using a Mycobacterium tuberculosis complex specific antibody for improved diagnosis of tuberculous lymphadenitis. Mod Pathol. 2006;19:1606-14.

74. Lamps LW, Madhusudhan KT, Greenson JK, et al. The role of Yersinia enterocolitica and Yersinia pseudotuberculosis in granulomatous appendicitis: a histologic and molecular study. Am J Surg Pathol. 2001;25:508-15.

75. Amarapurkar DN, Patel ND, Amarapurkar AD, et al. Tissue polymerase chain reaction in diagnosis of intestinal tuberculosis and Crohn's disease. J Assoc Physicians India. 2004;52:863-7.

76. Kisacik B, Pamuk ON, Onat AM, et al. Characteristics predicting tuberculosis risk under tumor necrosis factor-alpha inhibitors: report from a large multicenter cohort with high background prevalence. J Rheumatol. 2016;43:524-9.

77. Horsburgh CR Jr. Mycobacterium avium complex infection in the acquired immunodeficiency syndrome. $\mathrm{N}$ Engl $\mathrm{J}$ Med. 1991;324:1332-8.

78. Sun HY, Chen MY, Wu MS, et al. Endoscopic appearance of GI mycobacteriosis caused by the Mycobacterium avium complex in a patient with AIDS: case report and review. Gastrointest Endosc. 2005;61:775-9.

79. Klatt EC, Jensen DF, Meyer PR. Pathology of Mycobacterium avium-intracellulare infection in acquired immunodeficiency syndrome. Hum Pathol. 1987;18:709-14.

80. Dolmans RA, Boel CH, Lacle MM, et al. Clinical manifestations, treatment, and diagnosis of tropheryma whipplei infections. Clin Microbiol Rev. 2017;30:529-55.

81. Yan L, Yang C, Tang J. Disruption of the intestinal mucosal barrier in Candida albicans infections. Microbiol Res. 2013;168:389-95.

82. Lamps LW, Lai KK, Milner DA Jr.. Fungal infections of the gastrointestinal tract in the immunocompromised host: an update. Adv Anat Pathol. 2014;21:217-27.

83. Patterson TF, Kirkpatrick WR, White $M$, et al. Invasive aspergillosis. Disease spectrum, treatment practices, and outcomes. I3 Aspergillus Study Group. Med (Baltim). 2000;79: 250-60.

84. Kazan E, Maertens J, Herbrecht R, et al. A retrospective series of gut aspergillosis in haematology patients. Clin Microbiol Infect. 2011;17:588-94.

85. Petrikkos G, Skiada A, Lortholary O, et al. Epidemiology and clinical manifestations of mucormycosis. Clin Infect Dis. 2012;54:S23-34.

86. Colombo AL, Tobon A, Restrepo A, et al. Epidemiology of endemic systemic fungal infections in Latin America. Med Mycol. 2011:49:785-98.

87. Horwath MC, Fecher RA, Deepe GS Jr.. Histoplasma capsulatum, lung infection and immunity. Future Microbiol. 2015;10:967-75.

88. Assi MA, Sandid MS, Baddour LM, et al. Systemic histoplasmosis: a 15-year retrospective institutional review of 111 patients. Med (Baltim). 2007;86:162-9.

89. Deng Z, Ribas JL, Gibson DW, et al. Infections caused by Penicillium marneffei in China and Southeast Asia: review of eighteen published cases and report of four more Chinese cases. Rev Infect Dis. 1988;10:640-52.

90. Ko CI, Hung CC, Chen MY, et al. Endoscopic diagnosis of intestinal penicilliosis marneffei: report of three cases and review of the literature. Gastrointest Endosc. 1999;50:111-4.

91. Deng ZL, Connor DH. Progressive disseminated penicilliosis caused by Penicillium marneffei. Report of eight cases and differentiation of the causative organism from Histoplasma capsulatum. Am J Clin Pathol. 1985;84:323-7.

92. Girardin M, Greloz V, Hadengue A. Cryptococcal gastroduodenitis: a rare location of the disease. Clin Gastroenterol Hepatol. 2010;8:e28-29.

93. Washington K, Gottfried MR, Wilson ML. Gastrointestinal cryptococcosis. Mod Pathol. 1991;4:707-11.

94. Harris JR, Lockhart SR, Debess E, et al. Cryptococcus gattii in the United States: clinical aspects of infection with an emerging pathogen. Clin Infect Dis. 2011;53:1188-95.

95. Cama VA, Mathison BA. Infections by intestinal Coccidia and Giardia duodenalis. Clin Lab Med. 2015;35:423-44.

96. Agarwal S, Mayer L. Pathogenesis and treatment of gastrointestinal disease in antibody deficiency syndromes. J Allergy Clin Immunol. 2009;124:658-64.

97. Oberhuber G, Mesteri I, Kopf W, et al. Demonstration of Trophozoites of G. Lamblia inileal mucosal biopsy specimens 
may reveal giardiasis in patients with significantly inflamed parasite-free duodenal mucosa. Am J Surg Pathol. 2016;40:1280-5.

98. Oberhuber G, Kastner N, Stolte M. Giardiasis: a histologic analysis of 567 cases. Scand J Gastroenterol. 1997;32:48-51.

99. Robertson S, Arnold C, Montgomery E, et al. Duodenal giardiasis: lessons from a large tertiary hospital. Mod Pathol. 2015;28:187A.

100. Panarelli NC, Gobara N, Hoda RS, et al. Cytology preparations of formalin fixative aid detection of giardia in duodenal biopsy samples. Am J Surg Pathol. 2017;41:570-4.

101. Field AS, Milner DA Jr.. Intestinal microsporidiosis. Clin Lab Med. 2015;35:445-59.

102. Ryan U, Paparini A, Monis P, et al. It's official - Cryptosporidium is a gregarine: what are the implications for the water industry? Water Res. 2016;105:305-13.

103. Lai KK, Goyne HE, Hernandez-Gonzalo D, et al. Cystoisospora belli infection of the gallbladder in immunocompetent patients: a clinicopathologic review of 18 cases. Am J Surg Pathol. 2016;40:1070-4.
104. Gupta S, Narang S, Nunavath V, et al. Chronic diarrhoea in HIV patients: prevalence of coccidian parasites. Indian J Med Microbiol. 2008;26:172-5.

105. Milder JE, Walzer PD, Kilgore G, et al. Clinical features of strongyloides stercoralis infection in an endemic area of the United States. Gastroenterology. 1981;80:1481-8.

106. Genta RM. Dysregulation of strongyloidiasis: a new hypothesis. Clin Microbiol Rev. 1992;5:345-55.

107. Kishimoto K, Hokama A, Hirata T, et al. Endoscopic and histopathological study on the duodenum of Strongyloides stercoralis hyperinfection. World J Gastroenterol. 2008;14:1768-73.

108. Minematsu H, Hokama A, Makishi T, et al. Colonoscopic findings and pathologic characteristics of Strongyloides colitis: a case series. Digestion. 2011;83:210-4.

109. Levenhagen MA, Costa-Cruz JM. Update on immunologic and molecular diagnosis of human strongyloidiasis. Acta Trop. 2014; 135:33-43.

110. Thompson BF, Fry LC, Wells CD, et al. The spectrum of GI strongyloidiasis: an endoscopic-pathologic study. Gastrointest Endosc. 2004;59:906-10. 